\title{
Differential Plasticity of the GABAergic and Glycinergic Synaptic Transmission to Rat Lumbar Motoneurons after Spinal Cord Injury
}

\author{
Karina Sadlaoud, Sabrina Tazerart, Cécile Brocard, Céline Jean-Xavier, Paule Portalier, Frédéric Brocard, \\ Laurent Vinay, and Hélène Bras \\ Laboratoire Plasticité et Physio-Pathologie de la Motricité (Unité Mixte de Recherche 6196), Centre National de la Recherche Scientifique and Aix-Marseille \\ Université, 13402 Marseille, France
}

\begin{abstract}
Maturation of inhibitory postsynaptic transmission onto motoneurons in the rat occurs during the perinatal period, a time window during which pathways arising from the brainstem reach the lumbar enlargement of the spinal cord. There is a developmental switch in miniature IPSCs (mIPSCs) from predominantly long-duration GABAergic to short-duration glycinergic events. We investigated the effects of a complete neonatal [postnatal day $0(\mathrm{P} 0)$ ] spinal cord transection (SCT) on the expression of Glycine and GABA $\mathrm{A}_{\mathrm{A}}$ receptor subunits (GlyR and $\mathrm{GABA}_{\mathrm{A}} \mathrm{R}$ subunits) in lumbar motoneurons. In control rats, the density of GlyR increased from P1 to P7 to reach a plateau, whereas that of $\mathrm{GABA}_{\mathrm{A}} \mathrm{R}$ subunits dropped during the same period. In P7 animals with neonatal SCT (SCT-P7), the GlyR densities were unchanged compared with controls of the same age, while the developmental downregulation of $\mathrm{GABA}_{\mathrm{A}} \mathrm{R}$ was prevented. Whole-cell patch-clamp recordings of mIPSCs performed in lumbar motoneurons at P7 revealed that the decay time constant of miniature IPSCs and the proportion of GABAergic events significantly increased after SCT. After daily injections of the 5- $\mathrm{HT}_{2} \mathrm{R}_{\text {agonist } \mathrm{DOI} \text {, GABA }} \mathrm{R}$ immunolabeling on SCT-P7 motoneurons dropped down to values reported in control-P7, while GlyR labeling remained stable. A SCT made at P5 significantly upregulated the expression of $\mathrm{GABA}_{\mathrm{A}} \mathrm{R} 1$ week later with little, if any, influence on GlyR. We conclude that the plasticity of GlyR is independent of supraspinal influences whereas that of $\mathrm{GABA}_{\mathrm{A}} \mathrm{R}$ is markedly influenced by descending pathways, in particular serotoninergic projections.
\end{abstract}

\section{Introduction}

Glycine and GABA activate chloride-permeable ionotropic glycine and $\mathrm{GABA}_{\mathrm{A}}$ receptors (GlyRs and $\mathrm{GABA}_{\mathrm{A}} \mathrm{Rs}$ ) (Legendre, 2001; Fritschy and Brünig, 2003). In immature spinal neurons, GABA- and glycine-evoked potentials are depolarizing and often excitatory and may even trigger action potentials (Takahashi, 1984; Wu et al., 1992; Gao et al., 1998; Ziskind-Conhaim, 1998; Jean-Xavier et al., 2006), because of a high intracellular $\mathrm{Cl}^{-}$concentration, which favors $\mathrm{Cl}^{-}$efflux through $\mathrm{GABA}_{\mathrm{A}}$ - or glycine channels. Maturation of inhibition in the rat spinal cord occurs within the perinatal period (Gao and Ziskind-Conhaim, 1995), during which the effect of GABA and glycine shifts from excitatory to inhibitory (Jean-Xavier et al., 2007; Delpy et al., 2008).

\footnotetext{
Received Dec. 21, 2009; accepted Jan. 18, 2010.

This work was supported by The Dana and Christopher Reeve Foundation Grants VB1-0502- and VB2-0801-2 (to L.V.) and the French Institut pour la Recherche sur la Moelle épinière et l'Encéphale (to L.V.). K.S. received a grant from the Association Française contre les Myopathies (Grant 13912). S.T. received a grant from Fondation pour le Recherche Médicale (Grant FDT20081213783). We thank J. M. Fritschy for kindly providing primary antibodies against $\mathrm{GABA}_{\mathrm{A}} \mathrm{R} \alpha 1, \alpha 2, \alpha 3$, and $\alpha 5$ subunits; Claude Moretti and Pascal Weber, at the Imagery Service at the Institut de Biologie du Développement de Marseille Luminy, Marseille, France, for their assistance with confocal microscopy; and Nathalie Baril, UMR6149, Centre National de la Recherche Scientifique, 6149 Marseille, France, for anatomical MRI experiments. We are indebted to Dr. Henri Burnet for the statistical analysis.

Correspondence should be addressed to Hélène Bras, Laboratoire Plasticité et Physio-Pathologie de la Motricité (UMR6196), Centre National de la Recherche Scientifique and Aix-Marseille Université, 31 Chemin Joseph Aiguier, 13402 cedex 20 Marseille, France. E-mail: bras@dpm.cnrs-mrs.fr.

D01:10.1523/JNEUROSCI.6310-09.2010

Copyright $\odot 2010$ the authors $\quad 0270-6474 / 10 / 303358-12 \$ 15.00 / 0$
}

Concomitantly, the density of glycinergic currents increases whereas that of GABAergic currents decreases. During this period, serotoninergic projections arising from raphe nuclei are among the earliest axons to reach the lumbar segments (Rajaofetra et al., 1989) (for review, see Vinay et al., 2000). Neonatal removal of these supraspinal influences by spinal cord transection prevents the shift from depolarizing to hyperpolarizing IPSPs in lumbar motoneurons (Jean-Xavier et al., 2006), suggesting that the brain plays a pivotal role in the maturation of $\mathrm{Cl}^{-}$ homeostasis and therefore of inhibitory synaptic transmission. However, consequences of such a spinal lesion on the expression of receptors to inhibitory amino acids remain unknown.

$\mathrm{GABA}_{\mathrm{A}}$ Rs form pentameric complexes assembled from a family of at least 21 subunits $(\alpha 1-6, \beta 1-4, \gamma 1-4, \delta, \rho 1-3, \theta, \pi)$. The $\alpha$ subunits determines the kinetics of deactivation and/or desensitization of the channel and its pharmacological properties (Sigel et al., 1990; Gingrich et al., 1995). In the mature CNS, the $\alpha 1 \beta 2 \gamma 2$ combination represents the largest population of $\mathrm{GABA}_{\mathrm{A}} \mathrm{Rs}$, followed by $\alpha 2 \beta 3 \gamma 2$ and $\alpha 3 \beta 3 \gamma 2$, which are preponderant in spinal cord (Fritschy et al., 2003). The postnatal switch from fetal to adult expression of $\mathrm{GABA}_{\mathrm{A}} \mathrm{R}$ subtypes has been studied in the rat brain (Fritschy et al., 1994), but remains to be investigated in the spinal cord. The predominant adult isoform of the GlyR is composed of three $\alpha 1$ and two $\beta$ subunits (Legendre, 2001). In spinal motoneurons, the coexistence of GABA and glycine in axon terminals (Ornung et al., 1994; Taal and Holstege, 1994), their core- 
lease (Jonas et al., 1998) and the colocalization of postsynaptic GABA $_{\mathrm{A}}$ and GlyR (Baer et al., 2003) have been established. Both postsynaptic $\mathrm{GABA}_{\mathrm{A}}$ and GlyR at inhibitory synapses are aggregated in clusters whose formation is regulated by gephyrin, a submembrane scaffolding protein (Pfeiffer et al., 1984, Triller at al., 1985). In this study we combine quantitative immunocytochemistry and patch-clamp recordings to examine the effects of a neonatal spinal cord transection (SCT) on the developmental expression, organization and function of $\mathrm{GABA}_{\mathrm{A}} \mathrm{Rs}$ and GlyRs. We demonstrate a differential plasticity of these receptors in response to a spinal cord transection: the plasticity of GlyRs is independent from supraspinal influences whereas that of $\mathrm{GABA}_{\mathrm{A}} \mathrm{Rs}$ is markedly influenced by descending pathways, in particular, serotoninergic projections.

\section{Materials and Methods}

The experiments were performed on Wistar rats from the day of birth (postnatal day $0, \mathrm{P} 0$ ) to $\mathrm{P} 12$. All surgical and experimental procedures were made to minimize animal suffering and conformed to both the guidelines from the French Ministry for Agriculture and Fisheries, Division of Animal Rights and the European guidelines for the care and use of laboratory animals (Council Directive 86/6009/EEC).

\section{Spinal cord transection}

The spinal cord was transected at P0 or P5 as described previously (Norreel et al., 2003; Jean-Xavier et al., 2006). Rats were deeply anesthetized by hypothermia. After laminectomy, the spinal cord was transected at the T8-T10 level, and one to two segments of the cord were removed. The lesion cavity was then filled with sterile absorbable local hemostat Surgicoll (Johnson and Johnson). Skin incisions were sutured using fine thread and covered by Steri-Strips (3M Health Care). The completeness of spinal cord transection (SCT) was verified by anatomical magnetic resonance imagery (aMRI) (see supplemental Fig. 1, available at www. jneurosci.org as supplemental material) and/or by postmortem visual inspection of the lack of continuity between the spinal stumps. All MRI studies were performed $2 \mathrm{~h}$ after the lesion by means of a Bruker PharmaScan spectrometer ( 7 tesla magnet and $16 \mathrm{~cm}$ horizontal bore size) and a dedicated transmit-receive rat body-coil (linear birdcage coil with $62 \mathrm{~mm}$ inner diameter). Sagittal T2* ${ }^{\star}$-weighted images were performed at both P0 and P5 (FLASH gradient-echo sequence with TR/TE $=300 / 3.7$ $\mathrm{ms}$, flip angle $=30^{\circ}$, slice thickness $=0.5 \mathrm{~mm}, \mathrm{FOV}=19 \mathrm{~mm}$, matrix $=$ $256 \times 256$, number of averages $=4$ ).

\section{Retrograde labeling of triceps surae motoneurons}

All the analyses were performed on a homogeneous population of retrogradely identified lumbar spinal motoneurons. Fast blue (FB, $0.5 \%$ in $\mathrm{NaCl} 0.9 \%$, F-5756, Sigma, $3 \mu \mathrm{l}$ ) was injected bilaterally in the triceps surae (TS; ankle extensors) muscles of anesthetized animals at either P0, $\mathrm{P} 5$ or $\mathrm{P} 9$ for observations performed at $\mathrm{P} 1, \mathrm{P} 7$ and $\mathrm{P} 12$, respectively. P0 and $\mathrm{P} 5$ animals were anesthetized by hypothermia whereas at $\mathrm{P} 9$, anesthesia was induced by isoflurane inhalation (AErrane, DDG9623, Baxter). After FB injection, the animals were warmed until normal breathing had recovered, and returned to their mother. FB-retrograde labeling was restricted to a lateral column of spinal motoneurons located in the L4 lumbar segment.

\section{Pharmacological treatments}

The activation of serotonergic $5-\mathrm{HT}_{2}$ receptors $\left(5-\mathrm{HT}_{2}-\mathrm{Rs}\right)$ was performed by intraperitoneal administration of 2,5-dimethoxy-4-iodoamphetamine hydrochloride (DOI; Sigma) a 5- $\mathrm{HT}_{2}$-R agonist that crosses the blood-spinal cord barrier. From $\mathrm{P} 4$ to $\mathrm{P} 7$, transected $(n=6)$ animals received daily injections of $0.15 \mathrm{mg} / \mathrm{kg}$ DOI (Kim et al., 1999; Norreel et al., 2003) diluted in 50 $\mu \mathrm{l}$ of $\mathrm{NaCl}$. A control group of 6 transected animals received daily intraperitoneal injections of $50 \mu \mathrm{l}$ of $\mathrm{NaCl}$.

\section{Immunohistochemistry}

Immunohistology was processed on a total of $78 \mathrm{Wistar}$ rats at P1, P7 and $\mathrm{P} 12$. The first group (P1, $n=17$ rats) was composed of control nonoperated animals. The second group of 7-d-old animals included pups whose spinal cord was transected on the day of birth (SCT-P7, $n=20$ ) and controls (Control-P7, $n=13$ ). Similarly, animals of the third age group (P12) were either intact (Control-P12, $n=11$ ) or cord-transected (SCT-P12, $n=17$ ) 1 week before (i.e., P5).

The animals were deeply anesthetized by hypothermia at P1 and P7, or by isoflurane inhalation (P12 rats) and killed by decapitation. The lumbar spinal cord [L1-L6] was rapidly excised, immersed for $1 \mathrm{~h}$ in $20 \%$ sucrose and then embedded in capsules containing Tissutech (Sakura) quickly frozen by immersion in $100 \%$ ethanol kept at $-80^{\circ} \mathrm{C}$. Transverse spinal cord sections (20 $\mu \mathrm{m}$-thick) were cut with a cryostat (Microm) and mounted onto gelatinized slides. They were immersed in freshly depolymerized $2 \%$ paraformaldehyde in $0.15 \mathrm{~m}$ phosphate buffered saline (PBS, pH 7.4) for $30 \mathrm{~min}$ and rinsed in PBS.

\section{Antibodies and their dilutions}

Antibodies against $\mathrm{GABA}_{\mathrm{A}} \mathrm{R} \alpha 1, \alpha 2, \alpha 3$, and $\alpha 5$ subunit (respective dilutions: $1: 20,000,1: 10,000,1: 4000,1: 4000)$ raised in rabbit were a kind gift from J. M. Fritschy (Institute of Pharmacology and Toxicology, University of Zurich, Zurich, Switzerland) (Fritschy and Mohler, 1995; Fritschy et al., 1998; Sassoè-Pognetto et al., 2000). Immunocytochemical characterization of these antibodies has been described previously and their specificity demonstrated by means of mutant mice lacking the $\alpha 1, \alpha 2, \alpha 3$, or $\alpha 5$ subunit genes (Günther et al., 1995; Yee et al., 2005; Kralic et al., 2006). Immunocytochemistry showed a complete absence of immunolabeling of the $\mathrm{GABA}_{\mathrm{A}} \mathrm{R} \alpha 1, \alpha 2, \alpha 3$, and $\alpha 5$ subunit, in each respective mice (Kralic et al., 2006). The monoclonal mouse antibody bd-17 (US Biological, bovine, cat \# G1016; 1:400) directed against both $\beta 2$ and $\beta 3$ subunits of $\mathrm{GABA}_{\mathrm{A}} \mathrm{Rs}$, recognize the major $\mathrm{GABA}_{\mathrm{A}} \mathrm{R}$ subtypes in the CNS (McKernan and Whiting, 1996) expressed during postnatal development (Alvarez et al., 1996) and in adult spinal cord motoneurons (Fritschy et al., 1994; Bohlhalter et al., 1996). The mature form of the GlyR, GlyR $\alpha 1$, was detected with either the monoclonal antibody mAb2b (Connex, mouse, 1:80, catalog \# 28120 501-0 and Synaptic Systems (SySy), mouse 1:250, catalog \# 146111 ) or the polyclonal antibody pAb2b (Millipore Bioscience Research Reagents, rabbit, 1:100; catalog \# AB5052), depending on the other primary antibodies used for double immunofluorescence staining (Pfeiffer et al., 1984; Schröder et al., 1991; Liu and Wong-Riley, 2002; Baer et al., 2003). Both monoclonal or the polyclonal antibodies against GlyR $\alpha 1$ displayed punctuate fluorescence outlining the cell bodies and dendrites of motoneurons, and a quantitative analysis showed 95\% colocalization of the fluorescent clusters when using both antibodies (Lorenzo et al., 2007).

The expression of the $\alpha 2$ subunit, the embryonic form of GlyR, which rapidly decreases after birth in the rat spinal cord (Legendre, 2001) has not been considered. The presynaptic and postsynaptic sides of the GlyR were studied using antibodies against the neuronal glycine transporter GlyT2 and the postsynaptic anchoring protein Gephyrin (Pfeiffer et al., 1984; Kirsch et al., 1993), respectively. The antibody against GlyT2 (Millipore Bioscience Research Reagents, guinea pig antisera, 1:20,000), has been shown to be a reliable marker of glycinergic inputs (Poyatos et al., 1997; Spike et al., 1997). The antibody against gephyrin (mAb7a, 1:400; Synaptic Systems) raised against purified rat glycine receptors was highly specific for postsynaptic aggregates (Pfeiffer et al., 1984; Kirsch et al., 1993), and showed an absence of immunolabeling in gephyrin knock-out mice (Kneussel et al., 1999; Fischer et al., 2000).

For double immunofluorescence staining, sections were incubated overnight at $4^{\circ} \mathrm{C}$ in a mixture of primary antibodies raised in different hosts, diluted in PBS containing 2\% normal donkey serum, $0.2 \%$ Triton X100. After being washed in PBS $(3 \times 10 \mathrm{~min})$, the sections were immersed in a solution containing a mixture of fluorochrome-conjugated secondary antibodies (Alexa 488, 1:800, Invitrogen; Cy3, 1:500, Jackson ImmunoResearch; with respective emission waves at 518, $575 \mathrm{~nm}$ ) diluted in PBS containing 2\% normal donkey serum for $1 \mathrm{~h}$, at room temperature. Sections were then rinsed and coverslipped in immunomount medium (Vector Laboratories). All secondary antibodies were raised in donkey and affinity-purified to prevent species cross-reactivity. Control experiments consisted of omitting successively one of the 
primary antibodies in the double-staining combinations. They resulted in a complete absence of cross-reactivity between different immunoreactions.

\section{Confocal microscopy and quantitative analysis}

The patterns of immunolabeling were analyzed by means of a laser scanning confocal microscope (Zeiss LSM 510 META) at low (20×) or high magnification (Plan Apochromat $63 \times 1.4$ (N.A.) oil-immersion objective). At high magnification, only FB-retrogradely labeled TS motoneurons with visible nuclei were scanned, and for each soma, a stack of 4-7 confocal images including the nucleus was collected $(1024 \times 1024$ pixels spaced $1 \mu \mathrm{m}$ apart). Dendrites clearly emerging from the cell body and that could be followed up to $200 \mu \mathrm{m}$ from the soma were also analyzed. The optical sections were digitally zoomed to $2 \times$ or $2.4 \times($ pixel size $=$ $0.0049 \mu \mathrm{m}^{2}$ or $0.0036 \mu \mathrm{m}^{2}$, respectively). Triple fluorescent labelings were captured using frame-channel mode to avoid any cross talk between the channels. Each optical section resulted from two scanning averages. Excitation of the fluorochromes was performed with a diode laser set at $405 \mathrm{~nm}$ to detect FB, an argon ion laser set at $488 \mathrm{~nm}$ to detect Alexa Fluor 488, and a helium/neon laser set at $575 \mathrm{~nm}$ to detect Cy3.

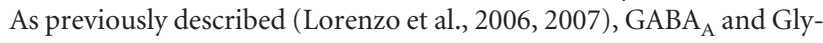
cine receptor subunits, GlyT2 and gephyrin clusters were defined based on size. They had to be composed of at least four adjacent pixels and did not exceed 12 pixels, which prevented double counting of the same clusters in adjacent images $1 \mu \mathrm{m}$ apart. The receptor density of each type of clustered receptor was determined by dividing the total number of fluorescent clusters outlining the motoneuron by its perimeter, measured by using the overlay tracing function of the Zeiss software (version 4). When the membrane immunolabeling was more diffuse (use of bd-17 antibody), the surface of the immunolabeled motoneuronal membrane was delimited by overlay and the averaged pixel intensity within this surface was quantified using the FluoView software (version 5).

\section{Electrophysiology}

Slice preparation. Whole-cell patch-clamp recordings were performed at P7 on control (Control-P7, $n=5$ ) and cord-transected rats (SCT-P7, $n=4)$. Animals were anesthetized by hypothermia. Quickly after decapitation, the spinal cord was isolated in cold $\left(4^{\circ} \mathrm{C}\right)$ and oxygenated $(95 \%$ of $\mathrm{O}_{2}$ and $5 \% \mathrm{CO}_{2}$ )sucrose solution of the following composition (in $\mathrm{mm}$ ): 232 sucrose, $3 \mathrm{KCl}, 1.25 \mathrm{KH}_{2} \mathrm{PO}_{4}, 4 \mathrm{MgSO}_{4}, 0.2 \mathrm{CaCl}_{2}, 26 \mathrm{NaHCO}_{3}, 25$ D-glucose (pH 7.4, $320 \mathrm{mOsm})$. After a section at the $\mathrm{L} 3$ level, the lumbar spinal cord was introduced into a $1 \%$ agar solution and quickly cooled. Transverse slices $(350 \mu \mathrm{m})$ through the L4-L5 lumbar segments were obtained and transferred into the holding chamber filled with oxygenated ACSF (in mm: $120 \mathrm{NaCl}, 3 \mathrm{KCl}, 1.25 \mathrm{NaH}_{2} \mathrm{PO}_{4}, 1.3 \mathrm{MgSO}_{4}, 1.2$ $\mathrm{CaCl}_{2}, 25 \mathrm{NaHCO}_{3}, 40$ D-glucose; $31^{\circ} \mathrm{C} \pm 2{ }^{\circ} \mathrm{C} ; \mathrm{pH}$ 7.4). One hour after dissection, slices were placed in the recording chamber filled with oxygenated ACSF and maintained at $30-32^{\circ} \mathrm{C}(2 \mathrm{ml} / \mathrm{min})$.

Data acquisition. Whole-cell voltage-clamp recordings were performed from large motoneurons (Multiclamp 700B amplifier, Digidata 1322A, pClamp 9 software, Molecular Devices). Slices were submerged in a chamber mounted on a fixed-stage microscope (Eclipse E600FN, Nikon, $40 \times$ water-immersion lens). Cells were visualized using differential interference contrast (DIC) optics associated with an infrared-sensitive CCD camera and displayed on a video monitor. Patch pipettes were made from borosilicate capillaries $(1.5 \mathrm{~mm}$ OD, $1.12 \mathrm{~mm}$ ID; World Precision Instruments) by means of a Sutter P-97 puller (Sutter Instruments Company). The resistance of electrodes was 2.5-4 $\mathrm{M} \Omega$ when filled with an intracellular solution containing the following (in $\mathrm{mm}$ ): $110 \mathrm{Cs}$ Chloride, $30 \mathrm{~K}^{+}$-gluconate, $5 \mathrm{NaCl}, 2 \mathrm{MgCl}_{2}, 10 \mathrm{HEPES}, 0.5 \mathrm{EGTA}, 2$ ATP, 0.4 GTP, pH 7.3 (280-290 mOsm). The series resistances that exceed $12 \mathrm{M} \Omega$ were discarded. Holding potential was $-70 \mathrm{mV}$. Signal was filtered at $4 \mathrm{kHz}$ and acquired at $10 \mathrm{kHz}$. To isolate miniature spontaneous IPSCs (mIPSCs), recordings were performed in the presence of tetrodotoxin (TTX, $1 \mu \mathrm{M}$ ) and kynurenic acid (1.5 mM). GABAergic and glycinergic mIPSCs were subsequently isolated by adding either strychnine $(1 \mu \mathrm{M})$ or bicuculline methiodide $(20 \mu \mathrm{M})$ to the ACSF solution. All pharmacological tools were purchased from Sigma-Aldrich except TTX purchased from Tocris Bioscience.
Data analysis. Data analysis was performed with the Minianalysis software (Synaptosoft). No difference in the background noise ( $3-4 \mathrm{pA})$ was observed between control animal and spinal cord transected group. Therefore, a threshold value $(\sim 6-8 \mathrm{pA})$ was set for event detection at two-fold the baseline noise. Cells with unstable baseline noise were discarded. All events were considered for frequency measurements. For the two other analyses (amplitude and decay time constant), only events starting from baseline were considered (superimposed events were discarded). The decay phase of pharmacologically isolated GABAergic and glycinergic events were best fitted by a single mono-exponential curve whereas mixed $\mathrm{GABA}_{\mathrm{A}}$ and glycinergic events were best fitted by a biexponential decay. Therefore, in normal ACSF, those events that had a biexponential decay (as revealed by the software) were classified as mixed events. Those with a mono-exponential decay were either GABAergic or glycinergic. Benzodiazepines, which slow the decay of $G_{A B A} R$ mediated mIPSCs, are sometimes used to improve the identification of GABAergic and glycinergic events on the basis of kinetic differences (Gao et al., 2001). These drugs were not used in the present study because their effects may be different in SCT animals compared with controls. Therefore we used the amplitude and the decay time constant $(\tau)$ to distinguish between GABAergic and glycinergic mIPSCs. Plotting $\tau$ against the current amplitude for pharmacologically isolated mIPSCs confirmed that GABA and glycinergic events had different characteristics: small amplitude/slow decay and large amplitude/fast decay, respectively (see Fig. 4A,B3). We determined a line that separates the two populations such that $\tau$ above or below this line would enable to identify the event as being GABAergic or glycinergic, respectively, with the smallest error $(<5 \%)$. The line with the following equation was used in the analysis of mIPSCs in control animals:

$$
\tau=(0.53 \times \text { amplitude })+1.67 ; \tau(\mathrm{ms}) ; \text { amplitude }(\mathrm{pA})
$$

Only $2.2 \%$ of GABAergic events and $4.8 \%$ of glycinergic events were below and above this line (errors). Because pharmacologically isolated mIPSCs had not exactly the same kinetics after SCT compared with controls (see Results), the line used for cord-transected animals had the following equation:

$$
\tau=(0.62 \times \text { amplitude })+2.27
$$

The percentages of errors in classifying GABAergic and glycinergic events based on the value of $\tau$ relative to this line were $2.6 \%$ and $3.0 \%$, respectively. These two lines were used to classify as GABAergic or glycinergic the events characterized by a mono-exponential decay in ACSF.

\section{Statistical analysis}

The data were analyzed as follows using the Sigmastat software (SPSS). The nonparametric one-way ANOVA (Kruskal-Wallis) was performed with a Dunn's post test for multiple comparisons between control animals and SCT and/or pharmacologically treated rats. Data were expressed as medians \pm QD (quartile deviation; Kendall and Buckland, 1960). The Wilcoxon matched-pairs-signed-ranks test was used to test for differences between receptor densities on cell bodies and dendrites. Statistical significance was taken at $p<0.05$. For electrophysiological data, all results are given as means \pm SEM. The Mann-Whitney test was used to compare two groups of data that followed non-Gaussian distributions (Prism 5; GraphPad Software Inc.).

The analysis in immunohistochemistry was performed on 1623 motoneurons retrogradely labeled and scanned at high magnification $(63 \times)$ in confocal microscopy. Every dual immunolabeling experiment was performed on histological sections from at least 3 transected and 3 agematched control animals. The number of analyzed motoneurons is indicated in the bar histograms.

\section{Results \\ Developmental expression of GlyRs and $\mathrm{GABA}_{\mathrm{A}} \mathrm{Rs}$ on TS motoneurons \\ GlyR $\alpha 1$}

The efficiency of glycinergic transmission depends on both (1) the proper alignment of presynaptic axon terminals and the postsynaptic receptor and (2) the anchoring of the membrane receptors to gephyrin (Schneider Gasser et al., 2006). Therefore, 

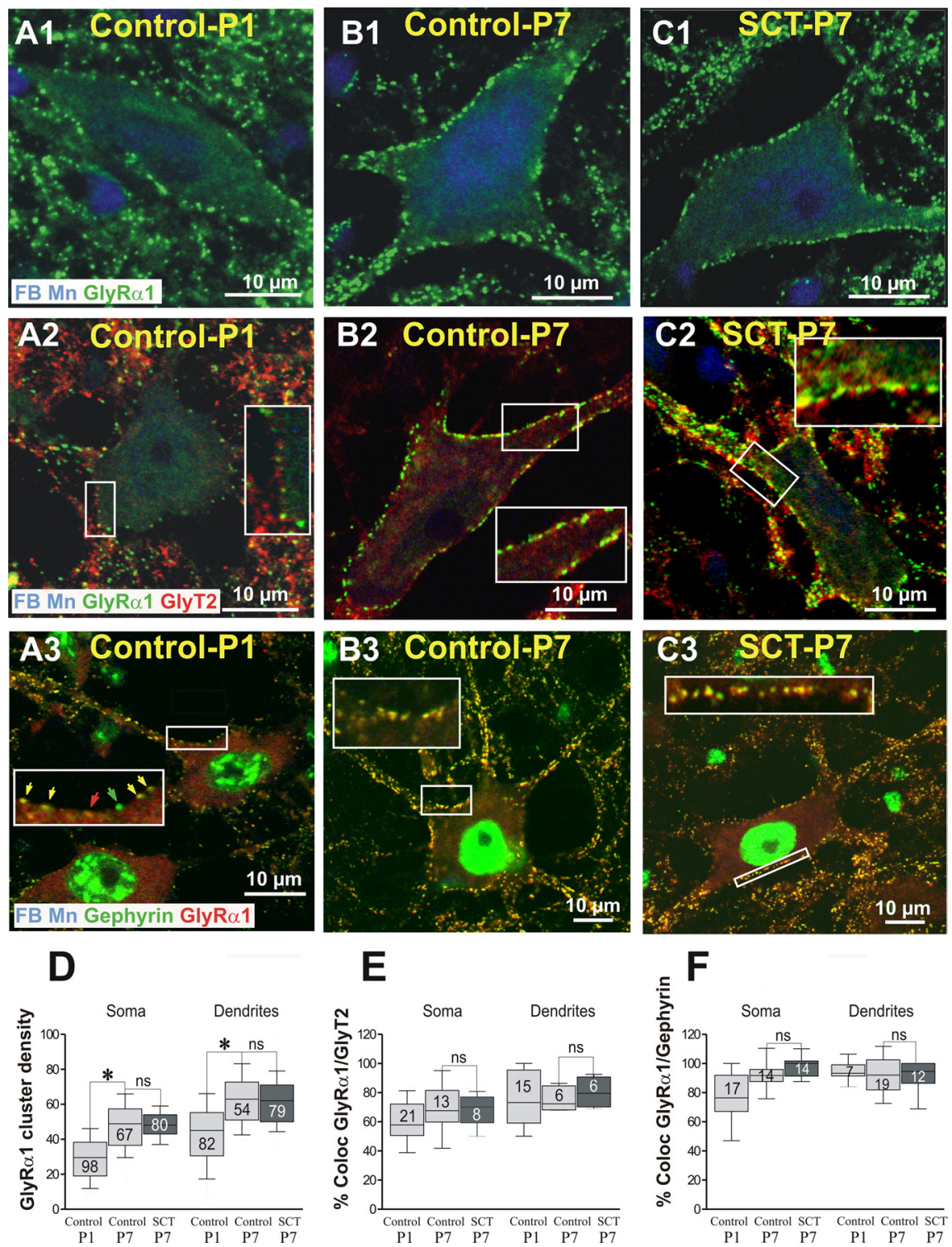

Figure 1. The developmental upregulation of GlyR is not affected by a neonatal SCT. Dual or triple labeling of GlyR $\alpha 1$ with GlyT2 and gephyrin on fast blue (FB) retrogradely identified TS motoneurons. The experiments were performed on control rats at P1 (control-P1), P7 (control-P7), and $7 \mathrm{~d}$ after neonatal SCT (SCT-P7). Each panel corresponds to a single optical section. In each horizontal series, the antigens detected (and their color of detection) are indicated in the lower part of the left panels. In control-P1 (A1), the density of GlyR $\alpha 1$ reached 29.5 clusters per $100 \mu \mathrm{m}$ on the cell bodies, 45 on the dendrites (Whiskers Box in $\boldsymbol{D}$ ). At this stage, $60 \%$ of the clusters of GlyR $\alpha 1$ faced GlyT2-immunoreactive axon terminals on the cell bodies, $75.1 \%$ on the dendrites (A2, $\boldsymbol{E}$ ), and $>75 \%$ of the GlyR $\alpha 1$ clusters were colocalized with gephyrin on the cell bodies, $94.8 \%$ on the dendrites $(\boldsymbol{A} \mathbf{3}, \boldsymbol{F})$. On motoneurons of control-P7 (B1), the rate of expression of the GlyR $\alpha 1$ significantly increased compared with control-P1 and their density reached 48.9 on the cell bodies, 62.9 on the dendrites ( $\boldsymbol{D}$; Kruskal-Wallis nonparametric test, $\mathrm{P} 1 \mathrm{vs} \mathrm{P} 7,{ }^{*} p<0.05$ ). At this stage, the association of GlyR $\alpha 1$ with GlyT2 reached $69.4 \%$ on the soma, $75.6 \%$ on the dendrites $(\boldsymbol{B 2}, \boldsymbol{E})$, while the colocalization of GlyR $\alpha 1$ with gephyrin was almost total on both soma $(91.8 \%)$ and dendrites $(91.7 \% ; \boldsymbol{B} 3, \boldsymbol{F})$. Seven days after neonatal SCT (SCT-P7), the density of GlyR $\alpha 1$-immunopositive clusters remained remarkably similar ( $(1)$ to those quantified on motoneurons of age matched-controls, on both cell bodies and dendrites ( $\boldsymbol{D}$; Control-P7 vs SCT-P7, $p=0.99$ for both soma and dendrites). The neonatal SCT did not significantly affect the rate of association of GlyR $\alpha 1$ with GlyT2 on both cell bodies (68.1\%) and dendrites (80.3\%) compared with P7-control animals ( $\mathbf{C}, \mathbf{E}$; Control-P7 vs SCT-P7; $p=0.11$ for soma and 0.8 for dendrites). Similarly, on SCT-P7 rats, the rate of colocalization of GlyR $\alpha 1$ with gephyrin (C3) did not significantly change compared with P7 animals on both soma (98.05\%) and dendrites (91.04\%; $F$; Control-P7 vs SCT-P7, $p=0.6$ for soma and 0.88 for dendrites).

we analyzed the development of the glycinergic synapse at presynaptic and postsynaptic levels, by quantifying the association of the GlyR $\alpha 1$ subunits with the presynaptic transporter GlyT2, and their colocalization with the anchoring protein gephyrin. All three immunolabelings (GlyR $\alpha 1$, GlyT2 and gephyrin) resulted in bright punctuate fluorescence (Fig. 1) which enabled to quan- tify the density of GlyR $\alpha 1$ on the membrane of TS motoneurons, and the rate of colocalization with GlyT2 or gephyrin. Immunofluorescent clusters of GlyR $\alpha 1$ and GlyT2 were adjacent, in line with a localization of GlyT2 at some distance from the glycine-releasing active zones (Zafra et al., 1995; Poyatos et al., 1997; Spike et al., 1997; Mahendrasingam et al., 2000). In contrast the dual immunolabeling of GlyR $\alpha 1$ and gephyrin resulted in overlapped clusters suggesting the closeness of both antigens.

At P1 (Fig. 1A1), the membrane of TS motoneurons was already enriched with immunofluorescent clusters of GlyR $\alpha 1$. Their density was higher on the dendrites than on the cell bodies (Fig. $1 D$, histograms). At this stage, $60 \%$ and $75 \%$ of the clusters of GlyR $\alpha 1$ faced GlyT2immunoreactive axon terminals on cell bodies and dendrites, respectively (Fig. $1 A 2, E)$, and $>75 \%$ of the GlyR $\alpha 1$ clusters were colocalized with gephyrin on the cell bodies $(94.8 \%$ on the dendrites; Fig. $1 A 3, F)$. At P7, the rate of expression of the GlyR $\alpha 1$ had significantly increased compared with P1 (Fig. 1B1,D). Their rates of association with GlyT2 increased compared with P1 (Fig. 1B2,E) and the large majority of GlyR $\alpha 1$ clusters were colocalized with gephyrin (Fig. 1B3,F).

\section{$G A B A_{A} R \alpha$}

Immunohistochemical experiments were performed using antibodies raised selectively against the $\alpha 1, \alpha 2, \alpha 3$, and $\alpha 5$ subunits of the $G_{A B A} R$. Every $G_{A B A} R$ subunit was covisualized with GlyR $\alpha 1$, used as a membrane indicator. The immunolabeling for the $\alpha 1, \alpha 2$, and $\alpha 3$ subunits of the $\mathrm{GABA}_{\mathrm{A}} \mathrm{R}$ resulted in a membrane punctuate fluorescence, associated with a homogeneous cytoplasmic labeling in agreement with previous observations (Fritschy et al., 1994; Bohlhalter et al., 1996; Geiman et al., 2002).

\section{$G A B A_{A} R \alpha 2$}

In control-P1 pups, immunopositive clusters of $\mathrm{GABA}_{\mathrm{A}} \mathrm{R} \alpha 2$ subunit were substantially expressed on the membrane of the motoneurons (Fig. 2A1) with median densities approximately twice higher on dendrites than on somata (28 vs 15 clusters per $100 \mu \mathrm{m}$; Fig. 2C1). Most of them were colocalized with GlyR $\alpha 1$ ( $84 \%$ and $82.6 \%$ on cell bodies and dendrites, respectively). In control-P7, only a few $\mathrm{GABA}_{\mathrm{A}} \mathrm{R} \alpha 2$ clusters remained expressed on the motoneuronal cell bodies (Fig. 2A2), and they were almost absent on the dendrites (Fig. 2C1). Their rate of colocalization with GlyR clusters decreased compared with P1, to $46.7 \%$ on the cell bodies and $31.3 \%$ on the dendrites. 
$G A B A_{A} R \alpha 3$

In control-P1, the density of $\mathrm{GABA}_{\mathrm{A}} \mathrm{R} \alpha 3$ was $\sim 8$ and 22 on cell bodies and dendrites, respectively (Fig. 2B1). The large majority of the $\mathrm{GABA}_{\mathrm{A}} \mathrm{R} \alpha 3$ ( $82 \%$ on both somata and dendrites) were colocalized with GlyR $\alpha 1$. At P7, these densities significantly decreased (Fig. 2 B2,C2; $p<0.05$ ).

$\mathrm{GABA}_{\mathrm{A}} \mathrm{R} \alpha 1$ and $\mathrm{GABA}_{\mathrm{A}} \mathrm{R} \alpha 5$ subunits were not expressed on the membrane of TS motoneurons in control-P1 and -P7 animals (supplemental Fig. 2A1,2; B1,2). The lack of $\mathrm{GABA}_{\mathrm{A}} \mathrm{R} \alpha 1$ on spinal motoneurons corroborates data obtained in adults (Bohlhalter et al., 1996) in line with a preferential expression of this subunit on specific brainstem motoneurons (Lorenzo et al., 2006), whereas the absence of $\mathrm{GABA}_{\mathrm{A}} \mathrm{R} \alpha 5$, which are classically described as extrasynaptic (Crestani et al., 2002; Fritschy and Brünig, 2003; Walker, 2008), suggest a weak contribution of a tonic inhibitory transmission in TS motoneurons of adult rats.

\section{Differential effects of a neonatal SCT on developmental expression of glycine and $\mathrm{GABA}_{\mathrm{A}}$ receptors}

Gly $\alpha R 1$

In SCT-P7 rats (Fig. 1C1,D), the densities of GlyR $\alpha 1$-immunopositive clusters on both cell bodies and dendrites remained remarkably close to those quantified in control-P7 motoneurons. In addition, the neonatal SCT affected neither the rate of association of GlyR $\alpha 1$ with GlyT2 (Fig. $1 C 2, E)$ nor the rate of colocalization of GlyR $\alpha 1$ with gephyrin (Fig. $1 C 3, F$ ).

We further determined the average GlyR $\alpha 1$ cluster size on the membrane of TS motoneurons of Control-P7 versus SCT-P7 (analysis of 484 clusters from 6 motoneurons in each series). The averaged GlyR $\alpha 1$ cluster size was not significantly different in control-P7 $\left(0.36 \mu \mathrm{m}^{2}\right)$ and SCT-P7 animals $\left(0.38 \mu \mathrm{m}^{2}, p=0.71\right.$; Mann-Whitney rank sum test, data not shown).

\section{$G A B A_{A} R \alpha 2$}

After neonatal SCT, the expression of the

$\mathrm{GABA}_{\mathrm{A}} \mathrm{R} \alpha 2$ did not undergo the normal developmental decrease. Indeed, median densities were significantly higher than at P7 (Fig. 2A3,C1; $p>0.05$ ) on both somata and dendrites and very similar to the values measured at $\mathrm{P} 1$. In addition, as observed in control-P1, a majority of $\mathrm{GABA}_{\mathrm{A}} \mathrm{R} \alpha 2$ clusters colocalized with GlyR $\alpha 1 \quad(90.8 \%$ on the cell bodies and $81.4 \%$ on the dendrites).

\section{$G A B A_{A} R \alpha 3$}

Similarly to the $\mathrm{GABA}_{\mathrm{A}} \mathrm{R} \alpha 2$, the age-related downregulation of the $\mathrm{GABA}_{\mathrm{A}} \mathrm{R} \alpha 3$ was prevented by the neonatal SCT (Fig. 2B3) such that median densities in SCT-P7 animals were significantly larger than in controls of the same age (Fig. 2C2; $p<0.05$ in both is indicated in each box.
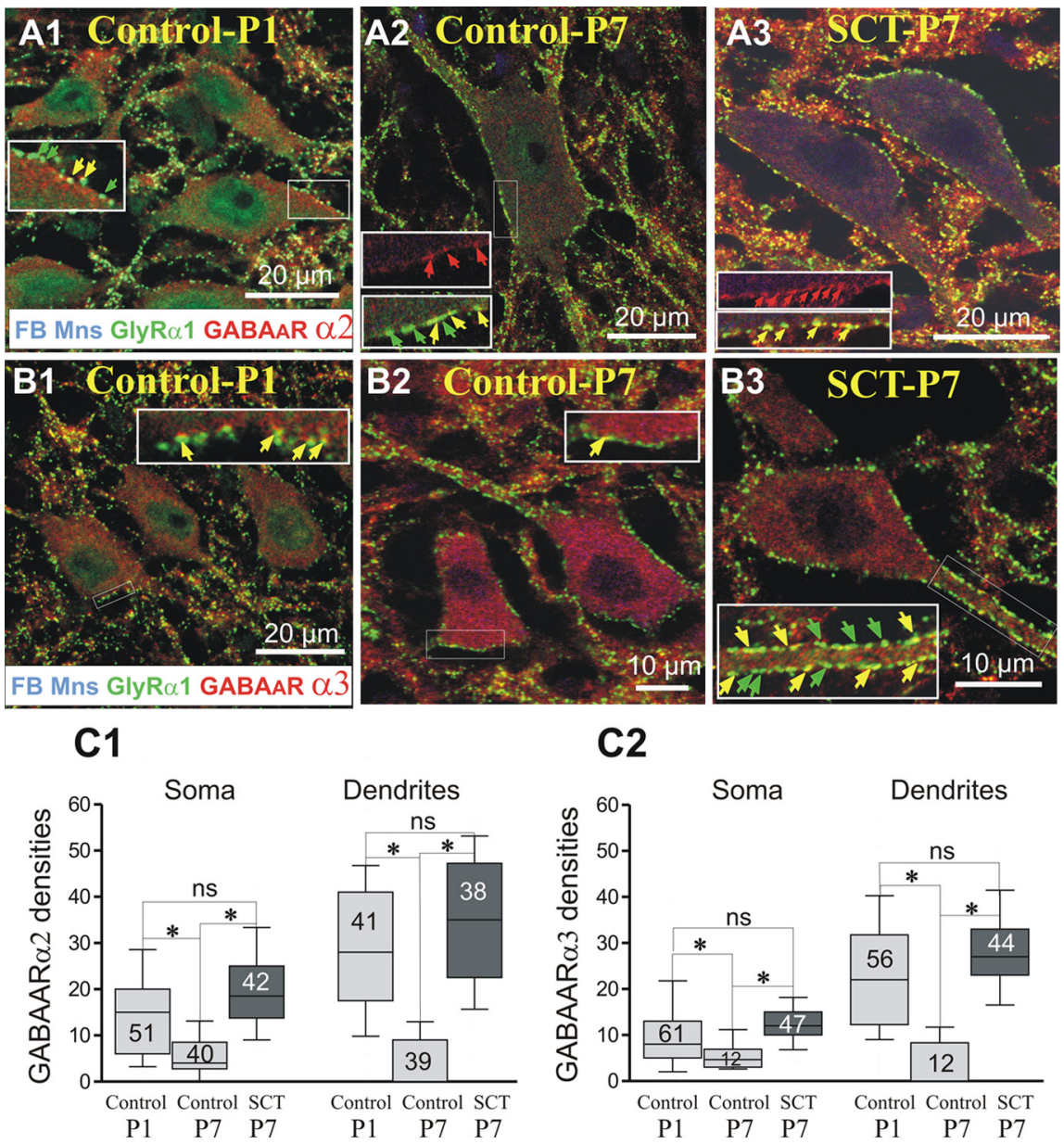

C2

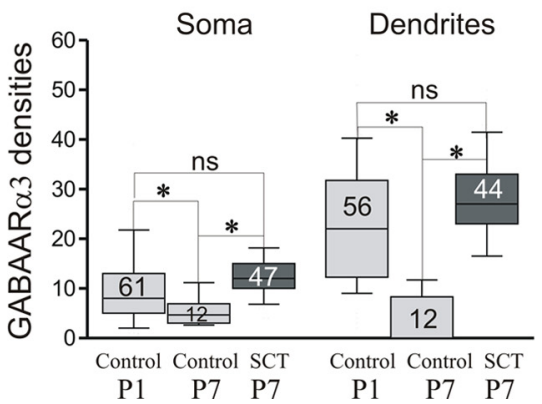

Figure 2. Lack of a developmental downregulation of the expression of $G A B A_{A} R \alpha 2$ and $G A B A_{A} R \alpha 3$ after neonatal SCT. Triple fluorescent labeling of GlyR $\alpha 1$ and $G A B A_{A} R \alpha 2$ or $G_{A B A} R \alpha 3$ on FB retrogradely identified TS motoneurons. Images are single optical plan sections. In each horizontal series, the antigens detected (and their color of detection) are indicated in the lower part (A1) with densities of 15 clusters per $100 \mu \mathrm{m}$ on the soma, 28 on the dendrites (C1, histograms). In control-P7, only a few $\mathrm{GABA}_{\mathrm{A}} \mathrm{R} \alpha 2$ clusters were still expressed on the motoneuronal membrane (A2), and their density significantly dropped down on control-P7; ${ }^{*} p<0.05$ in both soma and dendrites). After neonatal SCT, the expression of the $\mathrm{GABA}_{\mathrm{A}} \mathrm{R} \alpha 2$ did follow on a normal developmental decrease. Indeed, densities were significantly higher than in control-P7 (18.5 on the somata, 35 on the dendrites; v SCT-P7; $p>0.05$, on both somata and dendrites). A similar scenario was observed concerning $\mathrm{GABA}_{\mathrm{A}} \mathrm{R} \alpha 3$ : In control-P1 median density of $\mathrm{GABA}_{A} \mathrm{R} \alpha 3$ reached 8 on the soma, 22 on the dendrites (B1, $\mathbf{C 2}$ ). In control-P7, GABA $R \alpha 3$ densitie significantly decreased $(B 2)$ to $4 \pm 17$ on the soma, and $0.5 \pm 4$ on the dendrites $(p<0.05)$. After neonatal SCT the expression of the $\mathrm{GABA}_{\mathrm{A}} \mathrm{R} \alpha 3$ did not follow a normal developmental decrease (B3) and their densities (12 on soma, 27 on dendrites). Whiskers above and below the box indicate the $90^{\text {th }}$ and $10^{\text {th }}$ percentiles; the number of motoneurons analyzed

compartments), close to those in control-P1 (Fig. 2C2; $p>0.05$ ). The majority of $\mathrm{GABA}_{\mathrm{A}} \mathrm{R} \alpha 3$ clusters remained colocalized with GlyR $\alpha 1$ ( $86.7 \%$ on the cell bodies and $68.6 \%$ on the dendrites).

\section{$G A B A_{A} R \alpha 1$ and $G A B A_{A} R \alpha 5$}

Similarly to P1- and P7-control animals, an absence of membrane motoneuronal immunolabeling for both $\mathrm{GABA}_{\mathrm{A}} \mathrm{R} \alpha 1$ and $\mathrm{GABA}_{\mathrm{A}} \mathrm{R} \alpha 5$ subunits was evidenced $7 \mathrm{~d}$ after neonatal SCT (supplemental Fig. 2C1,2). However, in transected animals, $\mathrm{GABA}_{\mathrm{A}} \mathrm{R} \alpha 1$-immunopositive fibers were detected within the motoneuronal area most likely originating from an increased number of $\mathrm{GABA}_{\mathrm{A}} \mathrm{R} \alpha 1$-immunopositive interneurons observed medially to this area. 
Table 1. A neonatal spinal cord transection differentially changes the GABAergic and glycinergic mIPSC properties of motoneurons recorded at P7

\begin{tabular}{|c|c|c|c|c|c|c|c|c|}
\hline \multirow[b]{2}{*}{ Type of inhibition } & \multicolumn{4}{|c|}{ Control lumbar MNs } & \multicolumn{4}{|c|}{ Transected lumbar MNs } \\
\hline & $\tau(\mathrm{ms})$ & Ampl (pA) & Freq $(\mathrm{Hz})$ & $n$ & $\tau(\mathrm{ms})$ & Ampl (pA) & Freq $(\mathrm{Hz})$ & $n$ \\
\hline Control & $10.16 \pm 0.86$ & $36.33 \pm 5.38$ & $11.88 \pm 2.4$ & 8 & $15.61 \pm 1.25^{* *}$ & $25.03 \pm 3.94$ & $8.86 \pm 2.39$ & 9 \\
\hline GABA & $17.03 \pm 1.22$ & $15.27 \pm 2.31$ & $3.618 \pm 0.51$ & 5 & $21.92 \pm 0.58^{*}$ & $11.9 \pm 1.9$ & $4.157 \pm 1.08$ & 4 \\
\hline Glycine & $7.164 \pm 0.527$ & $43.91 \pm 7.58$ & $5.073 \pm 0.63$ & 5 & $6.356 \pm 0.65$ & $40.02 \pm 7.56$ & $7.818 \pm 2.28$ & 6 \\
\hline
\end{tabular}

Statistical significance was assessed by a Mann-Whitney test. ${ }^{*} p<0.05,{ }^{* *} p<0.01 . n=$ number of motoneurons.

\section{A1 Control-P7 mIPSCs}

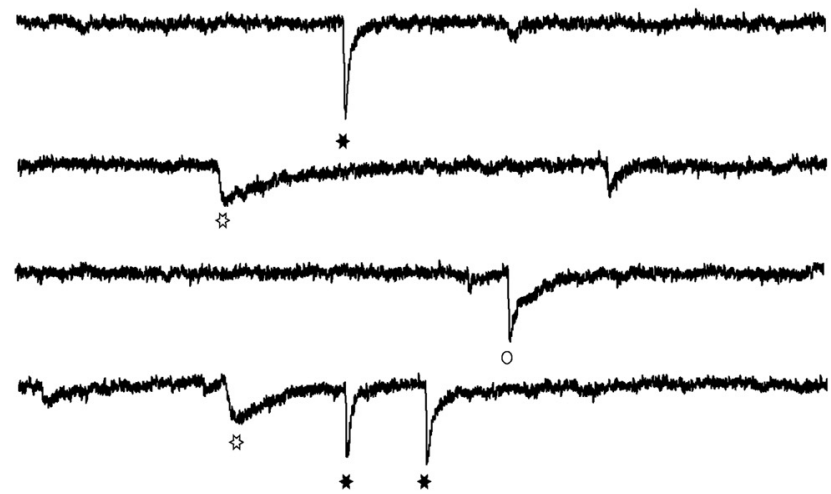

A2 SCT-P7 mIPSCs

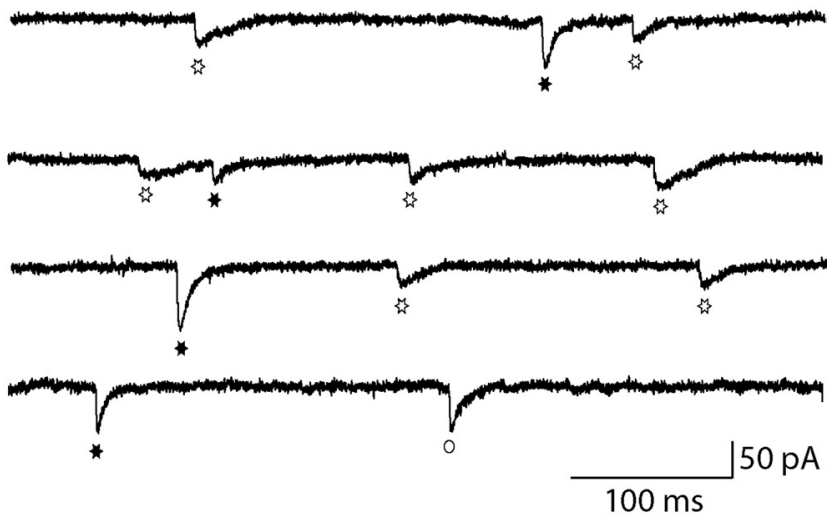

B1

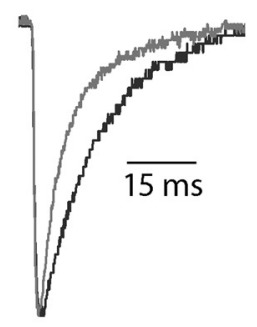

- Control-P7

- SCT-P7
B2

B3

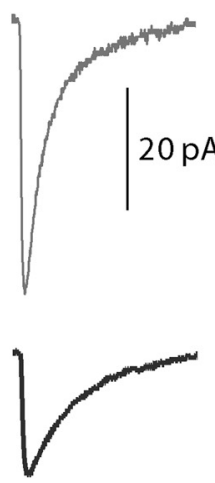

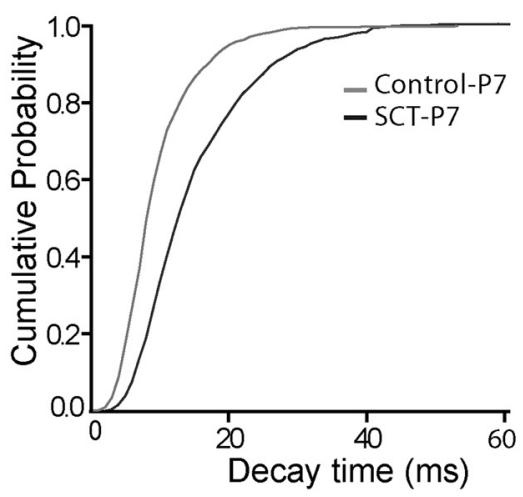

B4

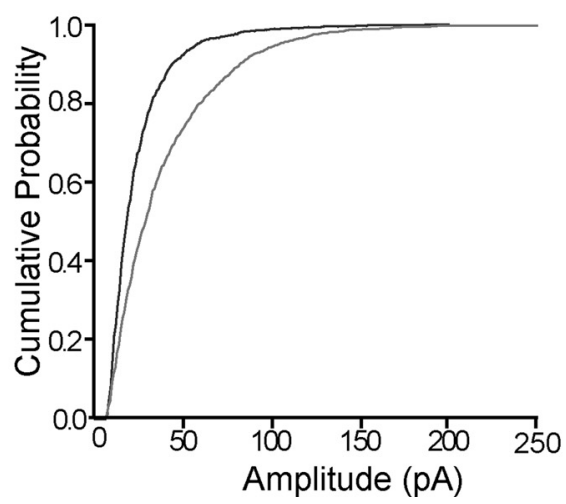

Figure 3. Deactivation decay time of global mIPSCs increase after SCT. A1, Example of mIPSCs from a motoneuron of control-P7 with glycine events (filled star), GABA ${ }_{A}$ events (open star), and mixed GABA/glycine events (open circle). A2, Example of mIPSCs from SCT-P7 motoneuron. B1, Normalized mean of mIPSCs from the control-P7 motoneuron illustrated in $\boldsymbol{A} 1$ (light gray trace, mean of 124 events) and from the SCT-P7 motoneuron illustrated in $\mathbf{A 2}$ (dark gray trace, mean of 114 events). B2, Mean of mIPSCs from the control-P7 motoneuron illustrated in $\boldsymbol{A} 1$ and from the SCT-P7 motoneuron illustrated in A2. B3, B4, Cumulative probability function of decay times and amplitudes for the individual events from control-P7 group (light gray traces; $n=2051$ events from 8 motoneurons) and from SCT-P7 group (dark gray traces; $n=2099$ events from 9 motoneurons). The mean decay time increased significantly after $S C T$ [10.16 \pm 0.86 ms in control group ( $n=8$ ) and $15.61 \pm 1.25 \mathrm{~ms}$ in SCT group $(n=9) ; p<0.01]$, whereas a nonsignificant trend toward a reduction of the amplitude of mIPSCs was observed after SCT ( $36.33 \pm 5.38 \mathrm{pA}$ vs $25.03 \pm 3.94 \mathrm{pA}$ in control and SCT group, respectively; $p>0.05$ ).

A neonatal SCT induces significant changes in GABAergic mIPSCs but not in glycinergic mIPSCs

Electrophysiological experiments were performed to investigate the functional correlate of these observations. Whole-cell patchclamp recordings were performed from motoneurons in the L4-L5 lumbar segments isolated from control-P7 and SCT-P7 animals. The frequency of mIPSCs in our conditions $\left(32^{\circ} \mathrm{C}\right)$ was $11.88 \pm 2.4 \mathrm{~Hz}$ (Table 1 ) and did not change significantly after neonatal SCT ( $8.86 \pm 2.39 ; p>0.05$; Table 1$)$. A global analysis of all mIPSCs revealed an increase $(\sim 50 \%)$ of the decay time constant $[\tau$ : mean $=10.16 \pm 0.86 \mathrm{~ms}$ vs $15.61 \pm 1.25 \mathrm{~ms}$ in control $(n=8)$ and SCT group $(n=9)$, respectively; $p<0.01, U=8.00$, Mann-Whitney test; Fig. 3B1,3; Table 1] and a nonsignificant trend toward a reduction of the amplitude of mIPSCs after SCT $($ mean $=36.33 \pm 5.38 \mathrm{pA}$ vs $25.03 \pm 3.94 \mathrm{pA}$ in control and SCT group, respectively; $p>0.05, U=18.00$, Mann-Whitney test; Fig. 3B2,4; Table 1). Cumulative distribution of mIPSCs decay times shifted to the right after SCT, indicating slower decay kinetics (Fig. 3B3), whereas the cumulative curve of amplitudes after SCT was slightly shifted to the left showing an overall decrease of event sizes (Fig. 3B4).

GABAergic and glycinergic events were isolated pharmacologically by adding strychnine or bicuculline, respectively (Fig. 4A1-3), and the kinetics of these events were analyzed. Our findings showed that $\tau$ of $\mathrm{GABA}_{\mathrm{A}} \mathrm{R}$-mediated mIPSCs was increased after SCT $(17.03 \pm 1.22 \mathrm{~ms}, n=5$ and $21.92 \pm 0.58 \mathrm{~ms}, n=4$ in control-P7 and SCT-P7 animals, respectively; $p<0.05, U=0.5$, Mann-Whitney test; Fig. 4B2; Table 1). The amplitude of GABA events decreased slightly after SCT $(15.27 \pm 2.31 \mathrm{pA}$ vs $11.9 \pm$ $1.9 \mathrm{pA} ; p>0.05, U=7.00$; Table 1$)$. For glycine events, both 
$\tau$ and the amplitude were unaffected by neonatal SCT (Fig. 4B1; Table 1).

To determine whether the respective proportions of GABAergic and glycinergic events were changed after SCT, we first calculated the percentage of pharmacologically isolated events, relative to the total number of mIPSCs recorded before drug application in the same motoneurons. The proportion of glycinergic events decreased $(66.66 \pm 7.37 \%$ vs $45.43 \pm$ 3.59\%; $p<0.05, U=2.00$, Mann-Whitney test) whereas that of $\mathrm{GABA}_{\mathrm{A}} \mathrm{R}$ mediated mIPSCs increased in animals with neonatal SCT $(25.48 \pm 6.61 \%$ vs $55.03 \pm 7.87 \% ; p<0.05, U=0.00$, Mann-Whitney test) (Fig. 4C1). We performed a second analysis based on the kinetics of mIPSCs recorded in ACSF (see Materials and Methods for the discrimination between the three types of currents). This method confirmed the $>100 \%$ increase in the proportion of GABAergic events $(21.53 \pm 5.247 \%$ vs $47.68 \pm 7.674 \% p<0.05 ; U=11.00$; Fig. $4 C 2$ ) and the $\sim 30 \%$ reduction in the percentage of glycinergic events (though not significant because of a large variability among cells) in SCT-P7 animals, compared with control-P7. Note that the proportion of pharmacologically isolated mIPSCs was larger than those calculated from the kinetics because they included both pure GABA or glycine events and mixed GABA/glycine events. The proportion of the latter events was not affected by SCT (Fig. 4C2). To summarize, these electrophysiological experiments are supporting the immunohistological results showing that $\mathrm{GABA}_{\mathrm{A}} \mathrm{Rs}$ are upregulated after neonatal spinal cord transection, compared with controls of the same age.

\section{A SCT performed at $\mathrm{P} 5$ upregulates $\mathrm{GABA}_{\mathrm{A}} \mathrm{Rs}$}

We next addressed the question of suppressing descending afferences several days after birth, when the levels of $\mathrm{GABA}_{\mathrm{A}} \mathrm{Rs}$ are already low in the lumbar cord, and when the reversal potential of IPSPs is significantly more negative than at birth (Stil et al., 2009). Four rats were transected at P5 and the spinal cords were processed for immunohistochemistry $7 \mathrm{~d}$ later (SCT-P12) together with tissues from 3 control-P12 animals. For both groups, GlyR $\alpha 1$ was covisualized with either $\mathrm{GABA}_{\mathrm{A}} \mathrm{R} \alpha 2$ or $\mathrm{GABA}_{\mathrm{A}} \mathrm{R} \alpha 3$.

\section{GlyR $\alpha 1$}

In control-P12, the densities of GlyR $\alpha 1$ ( $47 \pm 9.52$ on cell bodies, $60.7 \pm 8$ on the dendrites, Fig. $5 A 1)$ were similar to those observed in control-P7 (compare Figs. $1 D, 5 D ; p=0.99$ for both somata and dendrites), in line with a glycinergic transmission being already mature at P7. In SCT-P12 animals, these densi-

C1

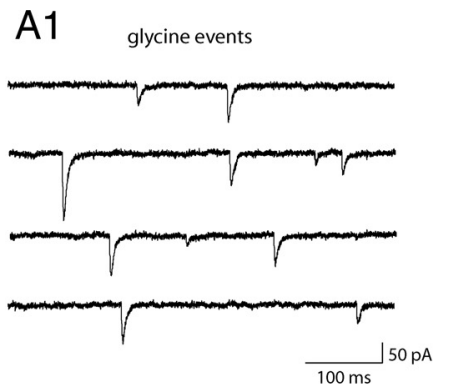

A2

GABAA events

B1

\section{B3}

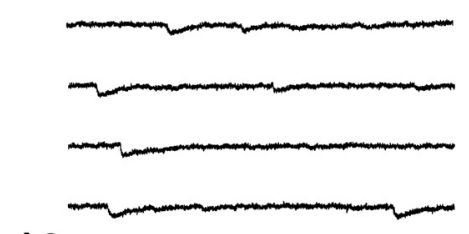

A3
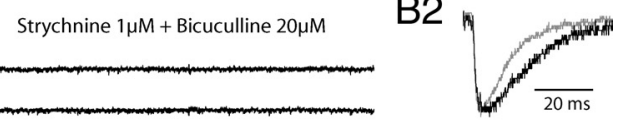
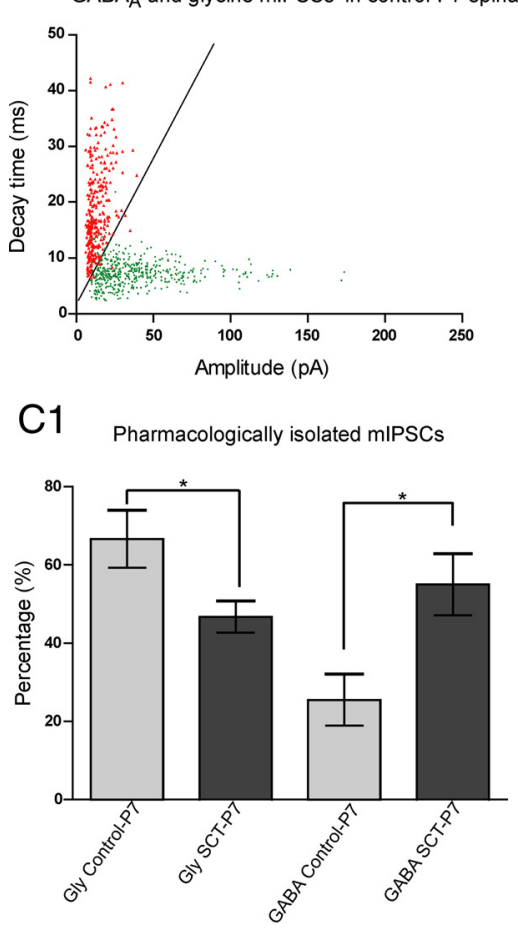

Figure 4. Increase of the proportion of GABAergic but not glycinergic or mixed GABA/Gly events after SCT. A1, Miniature glycinergic events were recorded after $20 \mathrm{~min}$ of bicuculline methiodide superfusion $(20 \mu \mathrm{M})$. $A \mathbf{2}$, GABAergic events were recorded after superfusion of strychnine $(1 \mu \mathrm{m})$ during $15 \mathrm{~min}$. A3, All mIPSCs were blocked by cocktails of strychnine and bicuculline. B1, Means of glycine events from control-P7 (light gray trace, 134 events) and SCT-P7 (dark gray trace, 112 events) motoneurons were superimposed and normalized. B2, Means of GABA events from control-P7 (light gray trace, 53 events) and SCT-P7 (dark gray trace, 39 events) were superimposed and normalized. B3, Cloud point representation of GABA (red triangles) and glycine (green dots) events after application of strychnine or bicuculline as a function of the amplitude and decay time of each event from control-P7 and SCT-P7 (517 glycine events in control-P7 $(n=5)$ and 646 glycine events in SCT-P7 $(n=6) ; 308$ GABA events in control-P7 $(n=5)$ and 329 in SCT-P7 $(n=4))$. C1, Histogram showing the percentages of pharmacologically isolated glycine and GABA vents, relative to the total number of mIPSCs recorded before drug application in the same motoneurons, in control-P7 (light gray bars) and in SCT-P7 (dark gray bars). C2, Histogram of percentage of glycine, GABA and mixed GABA/glycine events as function of kinetics, in control-P7 (light gray bars) and after SCT-P7 (dark gray bars).

ties remained unchanged (Fig. 5A2) in both compartments (Fig. $5 D ; p=1$ and 0.99 for somata and dendrites, respectively).

\section{$G A B A_{A} R \alpha 2$}

The density of $\mathrm{GABA}_{\mathrm{A}} \mathrm{R} \alpha 2$ on TS motoneurons was, in control-P12 (Fig. 6B1), as low as in control-P7 (compare Figs. $2 C 1,5 D ; p=0.97$ and 0.52 on somata and dendrites, respectively). In SCT-P12 rats, the densities significantly increased, compared with P12 (Fig. 5B2,D; $p<0.05$ on both compartments). These cluster densities on SCT-P12 motoneurons were significantly higher than those in control-P1 $(p<0.05$, somata and dendrites). 

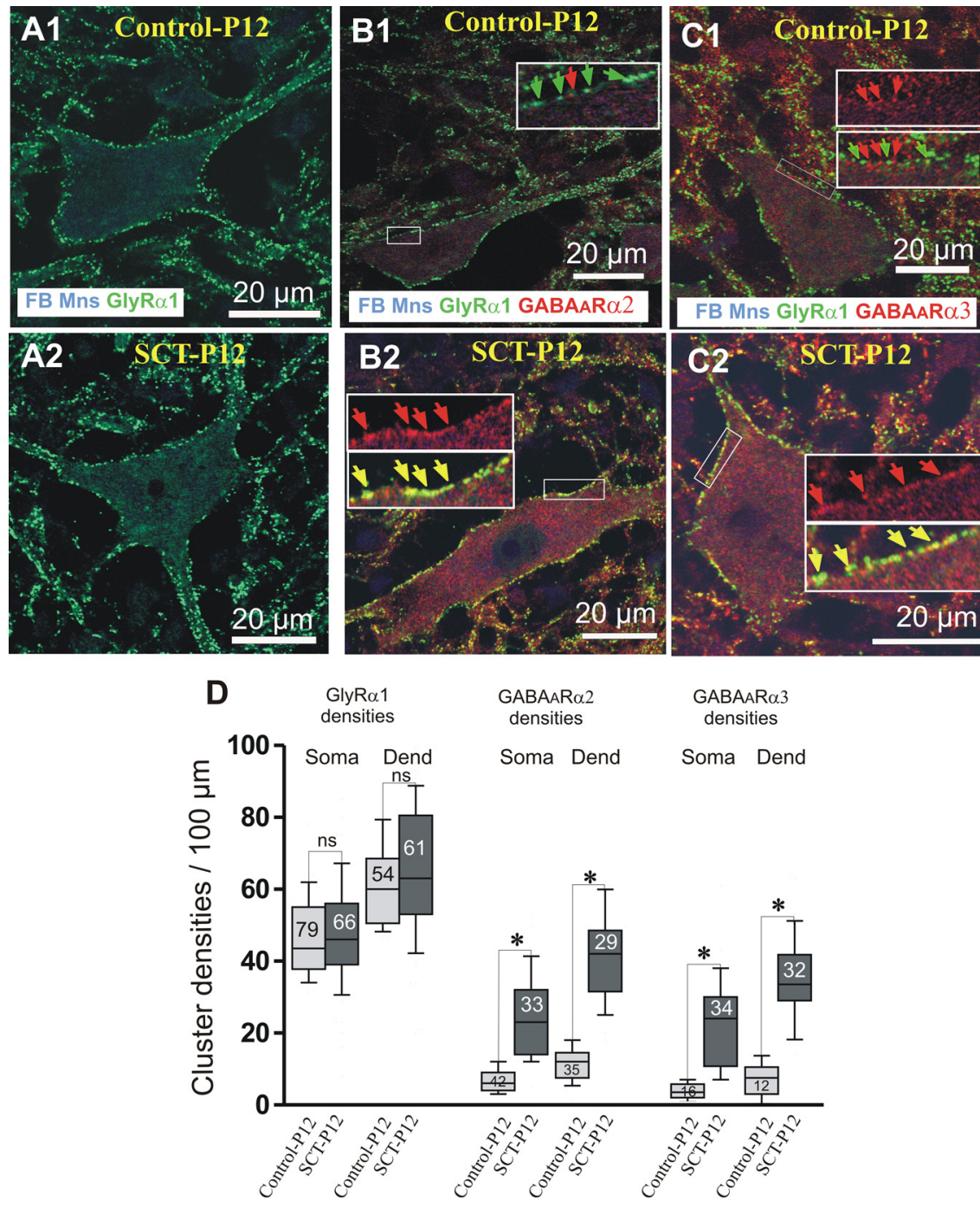

Figure 5. Effects of an $\mathrm{SCT}$ made on $\mathrm{P5}$, on the expression of $\mathrm{GABA}_{\mathrm{A}} \mathrm{R}$ and GlyR. To differentiate maturational and reactional postlesional effects, $\mathrm{SCT}$ was made at $\mathrm{P} 5$, when the levels of $\mathrm{GABA}_{\mathrm{A}} \mathrm{Rs}$ are already low in the lumbar cord. The effects of the lesion on the motoneuronal immunoexpression of GlyR $\alpha 1$ (green), $G A B A_{A} R \alpha 2$, and $G A B A_{A} R \alpha 3$ (red) were compared on fast bluelabeled motoneurons of control-P12 and on transected SCT-P12 animals. For each column, the combination of antibodies used is mentioned in the lower part of the upper picture. $\boldsymbol{A 1}, \boldsymbol{A 2}$, The membrane densities of GlyR $\alpha 1$ s observed on TS motoneurons of SCT-P12 animals remained unchanged compared with control-P12 rats ( $\boldsymbol{D}$ : control-P12 vs SCT-P12: $p=1$ and $p=0.9$ for soma and dendrites, respectively). $B 1, B 2$, On SCT-P12 rats, the cluster densities of $G A B A_{A} R \alpha 2$ significantly increased compared with control-P12. C1, C2, Similarly, the $G_{A B A} R \alpha 3$ densities were significantly higher on motoneurons of SCT-P12 rats than in controlP12 (D: control-P12 vs SCT-P12: $p<0.05$ for both somata and dendrites). Whiskers above and below the box indicate the $90^{\text {th }}$ and $10^{\text {th }}$ percentiles; the number of motoneurons analyzed is indicated in each box. (Kruskal-Wallis nonparametric test, ${ }^{*} p<0.05$; ns, nonsignificant).

\section{$G A B A_{A} R \alpha 3$}

The results for $G_{A B A} R \alpha 3$ were similar to those for $G_{A B A} R \alpha 2$. In control-P12 (Fig. 5C1), the densities of $\mathrm{GABA}_{\mathrm{A}} \mathrm{R} \alpha 3 \mathrm{~s}$ were close to values observed in control-P7 (Figs. $2 C 2,5 D ; p=0.43$ and 0.98 on cell bodies and dendrites, respectively). In SCT-P12 animals, the densities of $\mathrm{GABA}_{\mathrm{A}} \mathrm{R} \alpha 3$ significantly increased compared with both control-P12 and -P1 ( $p<0.05$ for both comparisons).

In SCT-P12 rats, the rates of colocalization of GlyR $\alpha 1$ with $\mathrm{GABA}_{\mathrm{A}} \mathrm{R} \alpha 2$ (cell bodies: 88.64\%; dendrites: 90.28\%) and $\mathrm{GABA}_{\mathrm{A}} \mathrm{R} \alpha 3$ (86.47\% and $84.24 \%$ on somata and dendrites, respectively) were not significantly different from those calculated in control-P1. These results lead to the conclusion that $7 \mathrm{~d}$ after a complete SCT made at $\mathrm{P} 5, \mathrm{GABA}_{\mathrm{A}} \mathrm{R} \alpha 2$ and $\mathrm{GABA}_{\mathrm{A}} \mathrm{R} \alpha 3$ are considerably upregulated at the surface of TS motoneurons. Their densities reached values significantly higher than those observed at birth, when the developmental downregulation of $\mathrm{GABA}_{\mathrm{A}} \mathrm{R}$ is not completed. In contrast, a transection made at $\mathrm{P} 5$ did not alter the expression of GlyR $\alpha 1$, thereby confirming that the developmental upregulation of this subunit is completed at the end of the first postnatal week.

\section{Activation of $5-\mathrm{HT}_{2} \mathrm{R}$ compensates the effect of SCT on the expression of $\mathrm{GABA}_{\mathrm{A}} \mathrm{R}$}

A neonatal SCT suppresses the action of pathways descending from the brainstem, in particular serotoninergic (5-HT) projections, on the lumbar enlargement. Since $5-\mathrm{HT}_{2}$ Rs play a key role in the modulation, development and recovery of motor function after spinal cord injury (Barbeau and Rossignol, 1990; Miller et al., 1996; Kim et al., 1999; Vinay et al., 2002; Norreel et al., 2003; Boulenguez and Vinay, 2009), we investigated whether the activation of $5-\mathrm{HT}_{2} \mathrm{Rs}$ would reduce the abnormal expression of $\mathrm{GABA}_{\mathrm{A}} \mathrm{R}$ subunits observed in TS motoneurons of SCT-P7 animals. Four rats with neonatal SCT received repeated intraperitoneal injection of DOI, a $5-\mathrm{HT}_{2}$ agonist, from $\mathrm{P} 4$ to P7. They were compared with three SCT-P7 rats which received equivalent volumes of $\mathrm{NaCl} 0.9 \%$ and with control P7 rats. To get an overall view of the effects of DOI on the GABA $\mathrm{A}$, bd-17 antibody, which is directed against both $\beta_{2}$ and $\beta_{3}$ subunits and therefore recognize the major $\mathrm{GABA}_{\mathrm{A}} \mathrm{R}$ subtypes in the CNS (Fritschy et al., 1994; Alvarez et al., 1996; McKernan and Whiting, 1996) was use and covisualized with the GlyR $\alpha 1$ on FBlabeled motoneurons (Fig. 6). In $\mathrm{NaCl}$ treated SCT-P7 rats, the median membrane fluorescence intensity of $\mathrm{GABA}_{\mathrm{A}} \beta_{2,3}$ was $583 \pm 146$ (Fig. 6A1,D1). In DOI-treated animals, this density significantly dropped down to values (Fig. $6 A 2-4 ; 265 \pm 143 ; p<0.05)$ that were not significantly different from those measured on control-P7 animals (Fig. $6 A 1 ; 285 \pm 120, p=0.13)$. In contrast, the membrane fluorescence intensity of GlyR $\alpha 1$ did not significantly change after DOI treatment (Fig. 6B1-4; SCT-P7-NaCl, $370 \pm 64$; SCT-P7-DOI, $497 \pm 105, p=0.35)$ and remained similar to that measured in control-P7 (Fig. 6B1). These results show that activation of $5-\mathrm{HT}_{2} \mathrm{Rs}$ with DOI enables the reversal of the upregulation of the expression of $\mathrm{GABA}_{\mathrm{A}} \mathrm{Rs}$ in ankle extensor motoneurons after SCT.

\section{Discussion}

Our results demonstrate that the removal of supraspinal influences on lumbar sensorimotor networks affects differentially the GABAergic and glycinergic synaptic transmission to triceps surae 

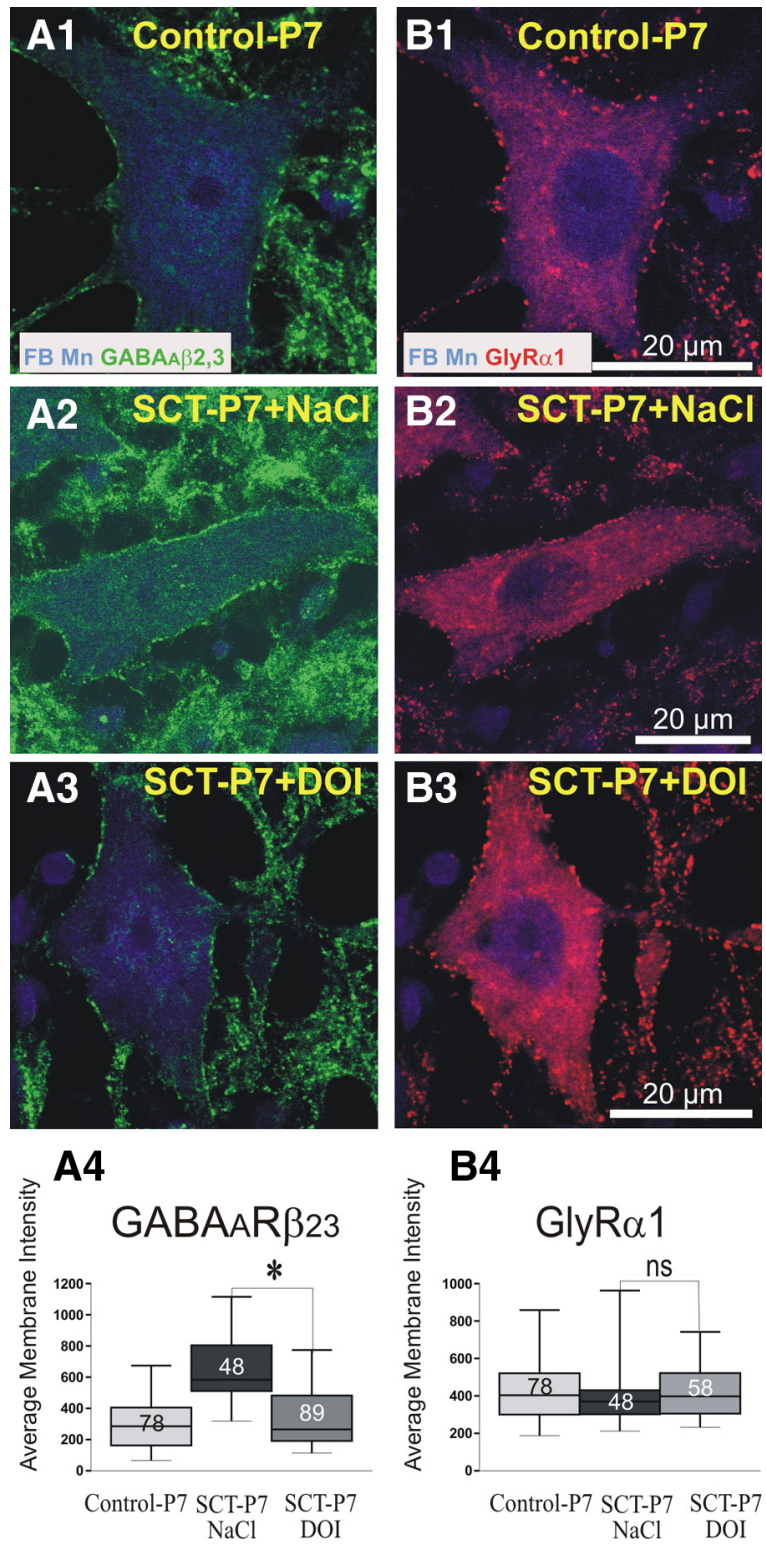

B4

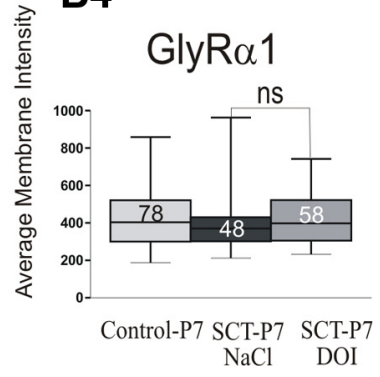

Figure 6. Effects of the activation of 5- $-\mathrm{HT}_{2} \mathrm{Rs}$ on the maturational expression of $\mathrm{GABA}_{\mathrm{A}} \mathrm{R}$ subunits and GlyR. Dual immunofluorescent labeling of $G_{A B} A_{A} R \beta_{2,3}$ subunits (left, Alexa 488, green) and GlyR $\alpha 1$ (right, $C y 3$, red) on $\mathrm{FB}$ retrogradely labeled TS motoneurons of control-P7 rats $(\boldsymbol{A} 1, \boldsymbol{B} 1)$, transected SCT-P7 rats treated with $\mathrm{NaCl}(\boldsymbol{A 2}, \boldsymbol{B 2}$, SCT-P7 + NaCl), and SCT-P7 rats treated with $D O I(A 3, B 3, S C T-P 7+D 0 I)$. Images are single optical plan sections. The antigens labeled are indicated in the lower part of the top. The average membrane fluorescence intensity of $G A B A_{A} R \beta_{2,3}$, which increased on motoneurons of SCT-P7-NaCl rats compared with control-P7, significantly dropped down on motoneurons of SCT-P7 + DOI animals (see histograms in $A 4 ; p<0.05$ ) to reach values observed in control-P7. In contrast, the average membrane fluorescence intensity of GlyR $\alpha 1$, which did not significantly change after SCT (compare histograms for control-P7 vs SCT-P7 rats treated with $\mathrm{NaCl}$ in B4) was not affected by the treatment with DOI (histograms in $B 4 ; p=0.35$ ). Whiskers above and below the box indicate the $90^{\text {th }}$ and $10^{\text {th }}$ percentiles; the number of motoneurons analyzed is indicated in each box. (Kruskal-Wallis nonparametric test, ${ }^{*} p<0.05$; ns, nonsignificant).

motoneurons. A neonatal SCT prevents the downregulation of $\mathrm{GABA}_{\mathrm{A}}$ receptors that normally occurs during the first postnatal week and a SCT performed at a later stage upregulates this system (Fig. 7). In contrast, the glycinergic system appears to be relatively insensitive to SCT. A downregulation of $\mathrm{GABA}_{\mathrm{A}}$ receptors, similar to what is observed during normal development was induced after SCT, by activating $5-\mathrm{HT}_{2}$ Rs. These data provide new per-

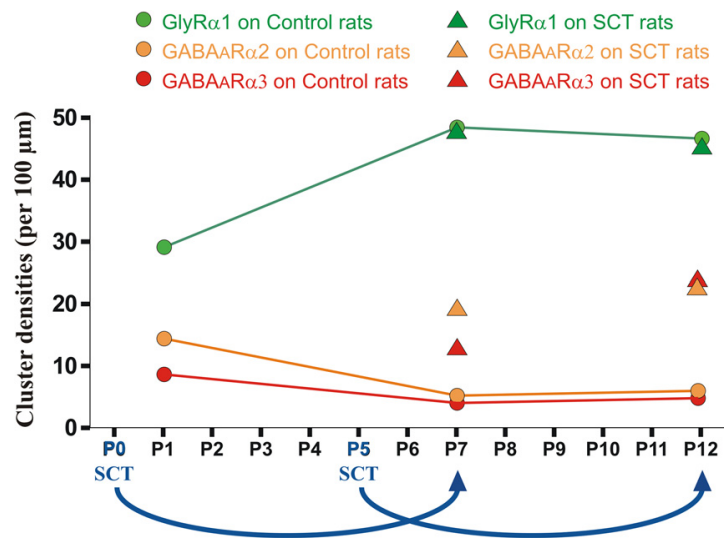

Figure 7. Summary of the analysis of cluster densities of GlyR $\alpha 1$ (green), $G_{A B A_{A}} R \alpha 2$ (orange), and $G A B A_{A} R \alpha 3$ (red) on the membrane of the cell bodies of TS motoneurons. Circles indicate membrane densities quantified in control rats at P1, P7, and P12, whereas triangles show the densities observed $7 \mathrm{~d}$ after a neonatal SCT or a SCT performed at P5. The glycinergic system appears to be relatively insensitive to SCT. In contrast, a neonatal SCT prevents the downregulation of $\mathrm{GABA}_{A}$ receptors that normally occurs during the first postnatal week and a SCT performed at a later stage (P5), when the expression of these receptors is low, upregulates this system.

spectives on the role of descending pathways in the plasticity of GABAergic and glycinergic systems.

\section{Postnatal development of GlyR and $\mathrm{GABA}_{\mathrm{A}} \mathrm{R}$ in TS motoneurons}

A transition from GABAergic to glycinergic synaptic transmission occurs at the level of lumbar motoneurons during perinatal development (Gao et al., 2001). Our results show that this maturation continues during the first postnatal week. At $\mathrm{P} 1$ the rate of expression of the $\alpha 1$-containing adult form of the GlyR reaches $70 \%$ of its maximal rate (P7), which is consistent with the early (P0) presence of GlyR $\alpha 1$ mRNA in rat spinal cord (Malosio et al., 1991). Both GlyT2 and gephyrin, shown to be critical for the functional clustering of the GlyR (Kneussel et al., 1999; Gomeza et al., 2003; Lévi et al., 2004), are highly associated with GlyR $\alpha 1$ at P1.

$\mathrm{GABA}_{\mathrm{A}}$ Rs are expressed early during ontogeny (E13), and $\alpha 1$, $\alpha 2, \alpha 3$ and $\alpha 5$ mRNAs are detected in the embryonic spinal cord (Ma et al., 1993). We show that at P1, only the $\mathrm{GABA}_{\mathrm{A}} \mathrm{R} \alpha 2$ and $\mathrm{GABA}_{\mathrm{A}} \mathrm{R} \alpha 3$ remain expressed on the surface of TS motoneurons. During the first postnatal week, the expression of both subunits decreases but they are still observed at P12, in agreement with in situ hybridization in adult rat lumbar spinal cord (Wisden et al., 1991). At P7, mixed GABA/glycine events represented $18 \%$ of the miniature IPSCs. This is close from observations made at P1-P3 (21\%; Gao et al., 2001) but smaller than those reported by Jonas et al. (1998) at P5-P10 (44\%). The discrepancy may result from the use of benzodiazepines (Chéry and de Koninck, 1999; Keller et al., 2001).

During the first postnatal week, we observed higher rates of expression of GlyR $\alpha 1$ and $\mathrm{GABA}_{\mathrm{A}} \mathrm{R}$ on proximal dendrites than on somata. Axo-dendritic inhibitory synapses evoke local shunt of the synaptic currents (Rall, 1959), which, on proximal dendrites, play pivotal roles by either blocking the back-propagation of the action potentials in the dendrites or controlling the weight of the excitatory inputs flowing along dendrites (Skydsgaard and Hounsgaard, 1994; Bras et al., 2003). 


\section{Differential effect of a complete thoracic SCT on the glycinergic and GABAergic systems}

In the rat, the first projections from the brainstem reach the lumbar cord before birth (E17) (Vinay et al., 2000) when inhibitory synaptic transmission is predominantly GABAergic. The number of descending axons reaching the lumbar cord then gradually increases until the second postnatal week (Lakke, 1997), when mature inhibitory synaptic transmission relies essentially on glycine (Gao et al., 2001). This overlap of the time windows raises the question of a possible causal link between the development of supraspinal control and inhibitory synaptic transmission. We therefore hypothesized that a neonatal SCT would maintain a P1-like pattern of expression of GlyR and $\mathrm{GABA}_{\mathrm{A}} \mathrm{R}$. This hypothesis was not confirmed for GlyR since after neonatal SCT, the densities of GlyR $\alpha 1$ and their rate of association with GlyT2 or gephyrin were not affected. Functionally, our electrophysiological data confirmed that the decay time, frequency and amplitude of glycinergic mIPSCs were unchanged after SCT. Although an over expression of the immature GlyR $\alpha 2$ cannot be ruled out, this hypothesis seems unlikely because the presence of this subunits would have lengthened the decay time of glycinergic events (Takahashi et al., 1992).

In contrast, the neonatal SCT resulted in a significant increase in the proportion of GABAergic events in SCT-P7 motoneurons. Immunohistochemistry strongly suggests that these changes result from a blockade or, at least a delay, of maturation. Indeed, on SCT-P7 motoneurons, the exclusive expression of $\mathrm{GABA}_{\mathrm{A}} \mathrm{R} \alpha 2$ and $\mathrm{GABA}_{\mathrm{A}} \mathrm{R} \alpha 3$, their density and rates of colocalization with both GlyR $\alpha 1$ and gephyrin were similar to those observed at P1. In SCT-P7 motoneurons, we also report that the decay time of GABA mIPSCs was longer than those measured in control-P7 motoneurons. This is also consistent with a blockade of maturation after SCT since a developmental decrease in the decay time constant of GABA events has been reported in lumbar or hypoglossal motoneurons (Gao et al., 2001; Muller et al., 2006) and in cortical neurons (Dunning et al., 1999). Furthermore, an increased intracellular concentration of $\mathrm{Cl}^{-}$ions slows down the kinetic of $\mathrm{GABA}_{\mathrm{A}}$ receptors (Houston et al., 2009). As a neonatal SCT prevents the hyperpolarizing shift of the chloride equilibrium potential that normally occur during the first postnatal week (Jean-Xavier et al., 2006), the resulting higher intracellular chloride concentration in SCT animals may also account for the slower $\mathrm{GABA}_{\mathrm{A}}$ kinetics. However, although glycine receptors are also sensitive to the intracellular $\mathrm{Cl}^{-}$concentration (Pitt et al., 2008), at this stage of the development, we did not observe any change in the kinetics of these receptors.

After neonatal transection, a left-right alternating locomotor pattern is observed in $\mathrm{P} 1-\mathrm{P} 3$ rats. It is gradually lost during the first postnatal week but reappears after activating $5-\mathrm{HT}_{2} \mathrm{Rs}$ with DOI (Norreel et al., 2003). This reversibility suggested that the synchrony resulted more from a disorganization of the alternating pattern than from the emergence of new pattern (Norreel et al., 2003). However, our data show that structural changes are not exclusively attributed to motoneurons, since an increased density of $\mathrm{GABA}_{\mathrm{A}} \mathrm{R} \alpha 1$-immunopositive fibers within the motoneuronal area (see supplemental Fig. 2, available at www.jneurosci.org as supplemental material) is observed after SCT. In addition, an increase in the $\mathrm{GABA}_{\mathrm{A}} \gamma 2$ subunits has been reported in astrocytes after neonatal SCT (Khristy et al., 2009). However, the effects of these changes on the network activity remain unknown. Interestingly, $24 \mathrm{~h}$ after spinal cord contusion made at P14, a significant decrease in the AMPA and NMDA receptor subunits has been reported (Brown et al., 2004), whereas the excitability of lumbar spinal networks is increased (Norreel et al., 2003). This seems inconsistent with the increased expression of $\mathrm{GABA}_{\mathrm{A}} \mathrm{R}$ observed in our study. However, IPSPs remain depolarizing from rest after neonatal SCT (Jean-Xavier et al., 2006). Depolarizing IPSPs have a reduced inhibitory strength, compared with hyperpolarizing IPSPs and can even exert facilitation on excitatory inputs (Jean-Xavier et al., 2007). The increased expression of $\mathrm{GABA}_{\mathrm{A}} \mathrm{R}$ can therefore lead to a higher excitability of neurons and networks.

Because activity-dependent mechanisms are important in the maturation of neurons and networks, the increased expression of $\mathrm{GABA}_{\mathrm{A}} \mathrm{R}$ in SCT animals can be due either to the lack of supraspinal influences or the resulting increased network activity. However, we showed that repeated activation of $5-\mathrm{HT}_{2} \mathrm{R}$ by DOI enabled to restore this downregulation. This strongly suggests a contribution of the serotonergic system to the maturation of the GABAergic system. Although the mechanisms underlying this interaction are unknown, several observations support a role of 5-HT in the modulation of the GABAergic system. (1) 5-HT descending inputs exert a negative control on the GABAergic phenotype during embryonic development (Allain et al., 2005). (2) The number of cells expressing glutamate decarboxylase mRNA (a marker of GABA synthesis) is increased below a lesion compared with intact animals and transplantation of embryonic raphe cells restores this number to control levels (Dumoulin et al., 2000). (3) Activation of 5- $\mathrm{HT}_{2 \mathrm{C}} \mathrm{Rs}$ produces a long-lasting inhibition of $\mathrm{GABA}_{\mathrm{A}} \mathrm{R}$ in Xenopus oocytes (Huidobro-Toro et al., 1996). A striking observation in the present study was the absence of effect of SCT on GlyR, suggesting that the development of this system relies neither on supraspinal influences nor on activitydependent mechanisms.

One week after a transection performed at P5, i.e., when inhibitory synaptic transmission is more mature, compared with $\mathrm{P} 0$, an over expression of the $\mathrm{GABA}_{\mathrm{A}} \mathrm{R}$ was observed, with rates of expression significantly higher than those in control-P1, whereas the densities of GlyRs remained unchanged. This dual effect of SCT on the glycinergic and GABAergic systems is consistent with results by Diaz-Ruiz et al. (2007) showing that the concentration of GABA increases shortly after spinal cord contusion in adult rats whereas that of glycine remains unchanged. Note, however that the glycinergic system may be affected at longer delays postinjury, as reported by Edgerton et al. (2001) 12 weeks after a SCT at P5 in rats. Furthermore, differential effects of transection on different neuronal populations, such as for instance flexor versus extensor motor pools (Khristy et al., 2009) cannot be ruled out.

To conclude, the present results provide additional evidence that postsynaptic inhibition is altered in the lumbar spinal cord after SCT (for review, see Vinay and Jean-Xavier, 2008; Boulenguez and Vinay, 2009). Chronic treatment with $5-\mathrm{HT}_{2} \mathrm{R}$ agonists partially restores locomotion in adult spinal rats (Antri et al., 2002). An intriguing hypothesis which will be tested further is that the activation of $5-\mathrm{HT}_{2} \mathrm{R}$ restores postsynaptic inhibition to control levels, in a way similar to training (Tillakaratne et al., 2002; Khristy et al., 2009).

\section{References}

Allain AE, Meyrand P, Branchereau P (2005) Ontogenic changes of the spinal GABAergic cell population are controlled by the serotonin (5-HT) system: implication of 5-HT1 receptor family. J Neurosci 25:8714-8724. Alvarez FJ, Taylor-Blake B, Fyffe RE, De Blas AL, Light AR (1996) Distribution of immunoreactivity for the beta 2 and beta 3 subunits of the GABAA receptor in the mammalian spinal cord. J Comp Neurol 365:392-412.

Antri M, Orsal D, Barthe JY (2002) Locomotor recovery in the chronic spi- 
nal rat: effects of long-term treatment with a 5-HT2 agonist. Eur J Neurosci 16:467-476.

Baer K, Waldvogel HJ, During MJ, Snell RG, Faull RL, Rees MI (2003) Association of gephyrin and glycine receptors in the human brainstem and spinal cord: an immunohistochemical analysis. Neuroscience 122:773784.

Barbeau H, Rossignol S (1990) The effects of serotonergic drugs on the locomotor pattern and on cutaneous reflexes of the adult chronic spinal cat. Brain Res 514:55-67.

Bohlhalter S, Weinmann O, Mohler H, Fritschy JM (1996) Laminar compartmentalization of GABAA-receptor subtypes in the spinal cord: an immunohistochemical study. J Neurosci 16:283-297.

Boulenguez P, Vinay L (2009) Strategies to restore motor functions after spinal cord injury. Curr Opin Neurobiol 19:587-600.

Bras H, Lahjouji F, Korogod SM, Kulagina IB, Barbe A (2003) Heterogeneous synaptic covering and differential charge transfer sensitivity among the dendrites of a reconstructed abducens motor neurone: correlations between electron microscopic and computer simulation data. J Neurocytol 32:5-24.

Brown KM, Wrathall JR, Yasuda RP, Wolfe BB (2004) Glutamate receptor subunit expression after spinal cord injury in young rats. Brain Res Dev Brain Res 152:61-68.

Chéry N, de Koninck Y (1999) Junctional versus extrajunctional glycine and GABA(A) receptor-mediated IPSCs in identified lamina I neurons of the adult rat spinal cord. J Neurosci 19:7342-7355.

Crestani F, Assandri R, Täuber M, Martin JR, Rudolph U (2002) Contribution of the alpha1-GABA(A) receptor subtype to the pharmacological actions of benzodiazepine site inverse agonists. Neuropharmacology 43:679-684.

Delpy A, Allain AE, Meyrand P, Branchereau P (2008) NKCC1 cotransporter inactivation underlies embryonic development of chloridemediated inhibition in mouse spinal motoneuron. J Physiol 586: $1059-1075$.

Diaz-Ruiz A, Salgado-Ceballos H, Montes S, Maldonado V, Tristan L, Alcaraz-Zubeldia M, Rios C (2007) Acute alterations of glutamate, glutamine, GABA, and other amino acids after spinal cord contusion in rats. Neurochem Res 32:57-63.

Dumoulin A, Privat A, Giménez y Ribotta M (2000) Transplantation of embryonic Raphe cells regulates the modifications of the gabaergic phenotype occurring in the injured spinal cord. Neuroscience 95:173-182.

Dunning DD, Hoover CL, Soltesz I, Smith MA, O'Dowd DK (1999) GABA(A) receptor-mediated miniature postsynaptic currents and alphasubunit expression in developing cortical neurons. J Neurophysiol 82:3286-3297.

Edgerton VR, Leon RD, Harkema SJ, Hodgson JA, London N, Reinkensmeyer DJ, Roy RR, Talmadge RJ, Tillakaratne NJ, Timoszyk W, Tobin A (2001) Retraining the injured spinal cord. J Physiol 533:15-22.

Fischer F, Kneussel M, Tintrup H, Haverkamp S, Rauen T, Betz H, Wässle H (2000) Reduced synaptic clustering of GABA and glycine receptors in the retina of the gephyrin null mutant mouse. J Comp Neurol 427:634-648.

Fritschy JM, Brünig I (2003) Formation and plasticity of GABAergic synapses: physiological mechanisms and pathophysiological implications. Pharmacol Ther 98:299-323.

Fritschy JM, Mohler H (1995) GABAA-receptor heterogeneity in the adult rat brain: differential regional and cellular distribution of seven major subunits. J Comp Neurol 359:154-194.

Fritschy JM, Paysan J, Enna A, Mohler H (1994) Switch in the expression of rat GABAA-receptor subtypes during postnatal development: an immunohistochemical study. J Neurosci 14:5302-5324.

Fritschy JM, Johnson DK, Mohler H, Rudolph U (1998) Independent assembly and subcellular targeting of GABA(A)-receptor subtypes demonstrated in mouse hippocampal and olfactory neurons in vivo. Neurosci Lett 249:99-102.

Fritschy JM, Schweizer C, Brünig I, Lüscher B (2003) Pre- and post-synaptic mechanisms regulating the clustering of type A gamma-aminobutyric acid receptors (GABAA receptors). Biochem Soc Trans 31:889-892.

Gao BX, Ziskind-Conhaim L (1995) Development of glycine- and GABAgated currents in rat spinal motoneurons. J Neurophysiol 74:113-121.

Gao BX, Cheng G, Ziskind-Conhaim L (1998) Development of spontaneous synaptic transmission in the rat spinal cord. J Neurophysiol 79:2277-2287.

Gao BX, Stricker C, Ziskind-Conhaim L (2001) Transition from GABAergic to glycinergic synaptic transmission in newly formed spinal networks. J Neurophysiol 86:492-502.

Geiman EJ, Zheng W, Fritschy JM, Alvarez FJ (2002) Glycine and GABA(A) receptor subunits on Renshaw cells: relationship with presynaptic neurotransmitters and postsynaptic gephyrin clusters. J Comp Neurol 444:275-289.

Gingrich KJ, Roberts WA, Kass RS (1995) Dependence of the GABAA receptor gating kinetics on the alpha-subunit isoform: implications for structure-function relations and synaptic transmission. J Physiol 489: 529-543.

Gomeza J, Ohno K, Hülsmann S, Armsen W, Eulenburg V, Richter DW, Laube B, Betz H (2003) Deletion of the mouse glycine transporter 2 results in a hyperekplexia phenotype and postnatal lethality. Neuron 40:797-806.

Günther U, Benson J, Benke D, Fritschy JM, Reyes G, Knoflach F, Crestani F, Aguzzi A, Arigoni M, Lang Y (1995) Benzodiazepine-insensitive mice generated by targeted disruption of the gamma 2 subunit gene of gammaaminobutyric acid type A receptors. Proc Natl Acad Sci U S A 92:77497753.

Houston CM, Bright DP, Sivilotti LG, Beato M, Smart TG (2009) Intracellular chloride ions regulate the time course of GABA-mediated inhibitory synaptic transmission. J Neurosci 29:10416-10423.

Huidobro-Toro JP, Valenzuela CF, Harris RA (1996) Modulation of GABAA receptor function by G protein-coupled 5-HT2C receptors. Neuropharmacology 35:1355-1363.

Jean-Xavier C, Pflieger JF, LiabeufS, Vinay L (2006) Inhibitory postsynaptic potentials in lumbar motoneurons remain depolarizing after neonatal spinal cord transection in the rat. J Neurophysiol 96:2274-2281.

Jean-Xavier C, Mentis GZ, O'Donovan MJ, Cattaert D, Vinay L (2007) Dual personality of GABA/glycine-mediated depolarizations in immature spinal cord. Proc Natl Acad Sci U S A 104:11477-11482.

Jonas P, Bischofberger J, Sandkühler J (1998) Corelease of two fast neurotransmitters at a central synapse. Science 281:419-424.

Keller AF, Coull JA, Chery N, Poisbeau P, De KY (2001) Region-specific developmental specialization of GABA-glycine cosynapses in laminas I-II of the rat spinal dorsal horn. J Neurosci 21:7871-7880.

Kendall MG, Buckland WR (1960) A dictionary of statistical terms, Ed 2. New York: Hafner.

Khristy W, Ali NJ, Bravo AB, de Leon R, Roy RR, Zhong H, London NJ, Edgerton VR, Tillakaratne NJ (2009) Changes in GABA(A) receptor subunit gamma 2 in extensor and flexor motoneurons and astrocytes after spinal cord transection and motor training. Brain Res 1273:9-17.

Kim D, Adipudi V, Shibayama M, Giszter S, Tessler A, Murray M, Simansky KJ (1999) Direct agonists for serotonin receptors enhance locomotor function in rats that received neural transplants after neonatal spinal transection. J Neurosci 19:6213-6224.

Kirsch J, Malosio ML, Wolters I, Betz H (1993) Distribution of gephyrin transcripts in the adult and developing rat brain. Eur J Neurosci 5:1109-1117.

Kitzman P (2007) VGLUT1 and GLYT2 labeling of sacrocaudal motoneurons in the spinal cord injured spastic rat. Exp Neurol 204:195-204.

Kneussel M, Brandstätter JH, Laube B, Stahl S, Müller U, Betz H (1999) Loss of postsynaptic $\mathrm{GABA}(\mathrm{A})$ receptor clustering in gephyrin-deficient mice. J Neurosci 19:9289-9297.

Kralic JE, Sidler C, Parpan F, Homanics GE, Morrow AL, Fritschy JM (2006) Compensatory alteration of inhibitory synaptic circuits in cerebellum and thalamus of gamma-aminobutyric acid type A receptor alpha1 subunit knockout mice. J Comp Neurol 495:408-421.

Lakke EA (1997) The projections to the spinal cord of the rat during development: a timetable of descent. Adv Anat Embryol Cell Biol 135:I-XIV, $1-143$.

Legendre P (2001) The glycinergic inhibitory synapse. Cell Mol Life Sci 58:760-793.

Lévi S, Logan SM, Tovar KR, Craig AM (2004) Gephyrin is critical for glycine receptor clustering but not for the formation of functional GABAergic synapses in hippocampal neurons. J Neurosci 24:207-217.

Liu Q, Wong-Riley MT (2002) Postnatal expression of neurotransmitters, receptors, and cytochrome oxidase in the rat pre-Botzinger complex. J Appl Physiol 92:923-934.

Lorenzo LE, Barbe A, Portalier P, Fritschy JM, Bras H (2006) Differential expression of GABAA and glycine receptors in ALS-resistant vs. ALS- 
vulnerable motoneurons: possible implications for selective vulnerability of motoneurons. Eur J Neurosci 23:3161-3170.

Lorenzo LE, Russier M, Barbe A, Fritschy JM, Bras H (2007) Differential organization of gamma-aminobutyric acid type $\mathrm{A}$ and glycine receptors in the somatic and dendritic compartments of rat abducens motoneurons. J Comp Neurol 504:112-126.

Ma W, Saunders PA, Somogyi R, Poulter MO, Barker JL (1993) Ontogeny of GABAA receptor subunit mRNAs in rat spinal cord and dorsal root ganglia. J Comp Neurol 338:337-359.

Mahendrasingam S, Wallam CA, Hackney CM (2000) An immunogold investigation of the relationship between the amino acids GABA and glycine and their transporters in terminals in the guinea-pig anteroventral cochlear nucleus. Brain Res 887:477-481.

Malosio ML, Marquèze-Pouey B, Kuhse J, Betz H (1991) Widespread expression of glycine receptor subunit mRNAs in the adult and developing rat brain. EMBO J 10:2401-2409.

McKernan RM, Whiting PJ (1996) Which GABAA-receptor subtypes really occur in the brain? Trends Neurosci 19:139-143.

Miller JF, Paul KD, Lee RH, Rymer WZ, Heckman CJ (1996) Restoration of extensor excitability in the acute spinal cat by the 5-HT2 agonist DOI. J Neurophysiol 75:620-628.

Muller E, Le Corronc H, Triller A, Legendre P (2006) Developmental dissociation of presynaptic inhibitory neurotransmitter and postsynaptic receptor clustering in the hypoglossal nucleus. Mol Cell Neurosci 32:254-273.

Norreel JC, Pflieger JF, Pearlstein E, Simeoni-Alias J, Clarac F, Vinay L (2003) Reversible disorganization of the locomotor pattern after neonatal spinal cord transection in the rat. J Neurosci 23:1924-1932.

Ornung G, Shupliakov O, Ottersen OP, Storm-Mathisen J, Cullheim S (1994) Immunohistochemical evidence for coexistence of glycine and GABA in nerve terminals on cat spinal motoneurones: an ultrastructural study. Neuroreport 5:889-892.

Pfeiffer F, Simler R, Grenningloh G, Betz H (1984) Monoclonal antibodies and peptide mapping reveal structural similarities between the subunits of the glycine receptor of rat spinal cord. Proc Natl Acad Sci U S A 81:7224-7227.

Pitt SJ, Sivilotti LG, Beato M (2008) High intracellular chloride slows the decay of glycinergic currents. J Neurosci 28:11454-11467.

Poyatos I, Ponce J, Aragón C, Giménez C, Zafra F (1997) The glycine transporter GLYT2 is a reliable marker for glycine-immunoreactive neurons. Brain Res Mol Brain Res 49:63-70.

Rajaofetra N, Sandillon F, Geffard M, Privat A (1989) Pre- and post-natal ontogeny of serotonergic projections to the rat spinal cord. J Neurosci Res 22:305-321.

Rall W (1959) Branching dendritic trees and motoneuron membrane resistivity. Exp Neurol 1:491-527:491-527.

Sassoè-Pognetto M, Fritschy JM (2000) Mini-review: gephyrin, a major postsynaptic protein of GABAergic synapses. Eur J Neurosci 12:22052210.

Schneider Gasser EM, Straub CJ, Panzanelli P, Weinmann O, SassoèPognetto M, Fritschy JM (2006) Immunofluorescence in brain sections: simultaneous detection of presynaptic and postsynaptic proteins in identified neurons. Nat Protoc 1:1887-1897.

Schröder S, Hoch W, Becker CM, Grenningloh G, Betz H (1991) Mapping of antigenic epitopes on the alpha 1 subunit of the inhibitory glycine receptor. Biochemistry 30:42-47.

Sigel E, Baur R, Trube G, Möhler H, Malherbe P (1990) The effect of subunit composition of rat brain GABAA receptors on channel function. Neuron 5:703-711.

Skydsgaard M, Hounsgaard J (1994) Spatial integration of local transmitter responses in motoneurones of the turtle spinal cord in vitro. J Physiol 479:233-246.

Spike RC, Watt C, Zafra F, Todd AJ (1997) An ultrastructural study of the glycine transporter GLYT2 and its association with glycine in the superficial laminae of the rat spinal dorsal horn. Neuroscience 77:543-551.

Stil A, Liabeuf S, Jean-Xavier C, Brocard C, Viemari JC, Vinay L (2009) Developmental up-regulation of the potassium-chloride cotransporter type 2 in the rat lumbar spinal cord. Neuroscience 164:809-821.

Taal W, Holstege JC (1994) GABA and glycine frequently colocalize in terminals on cat spinal motoneurons. Neuroreport 5:2225-2228.

Takahashi K (1984) [Development of excitable membrane in an early embryo]. Tanpakushitsu Kakusan Koso 29:1889-1898.

Takahashi T, Momiyama A, Hirai K, Hishinuma F, Akagi H (1992) Functional correlation of fetal and adult forms of glycine receptors with developmental changes in inhibitory synaptic receptor channels. Neuron 9:1155-1161.

Taketo M, Yoshioka T (2000) Developmental change of GABA(A) receptormediated current in rat hippocampus. Neuroscience 96:507-514.

Tillakaratne NJ, de Leon RD, Hoang TX, Roy RR, Edgerton VR, Tobin AJ (2002) Use-dependent modulation of inhibitory capacity in the feline lumbar spinal cord. J Neurosci 22:3130-3143.

Triller A, Cluzeaud F, Pfeiffer F, Betz H, Korn H (1985) Distribution of glycine receptors at central synapses: an immunoelectron microscopy study. J Cell Biol 101:683-688.

Vinay L, Jean-Xavier C (2008) Plasticity of spinal cord locomotor networks and contribution of cation-chloride cotransporters. Brain Res Rev 57:103-110.

Vinay L, Brocard F, Clarac F (2000) Differential maturation of motoneurons innervating ankle flexor and extensor muscles in the neonatal rat. Eur J Neurosci 12:4562-4566.

Vinay L, Brocard F, Clarac F, Norreel JC, Pearlstein E, Pflieger JF (2002) Development of posture and locomotion: an interplay of endogenously generated activities and neurotrophic actions by descending pathways. Brain Res Brain Res Rev 40:118-129.

Walker MC (2008) GABAA receptor subunit specificity: a tonic for the excited brain. J Physiol 586:921-922.

Wisden W, Gundlach AL, Barnard EA, Seeburg PH, Hunt SP (1991) Distribution of GABAA receptor subunit mRNAs in rat lumbar spinal cord. Brain Res Mol Brain Res 10:179-183.

Wu WL, Ziskind-Conhaim L, Sweet MA (1992) Early development of glycine- and GABA-mediated synapses in rat spinal cord. J Neurosci 12:3935-3945.

Yee BK, Keist R, von Boehmer L, Studer R, Benke D, Hagenbuch N, Dong Y, Malenka RC, Fritschy JM, Bluethmann H, Feldon J, Möhler H, Rudolph U (2005) A schizophrenia-related sensorimotor deficit links alpha 3-containing GABAA receptors to a dopamine hyperfunction. Proc Natl Acad Sci U S A 102:17154-17159.

Zafra F, Gomeza J, Olivares L, Aragón C, Giménez C (1995) Regional distribution and developmental variation of the glycine transporters GLYT1 and GLYT2 in the rat CNS. Eur J Neurosci 7:1342-1352.

Ziskind-Conhaim L (1998) Physiological functions of GABA-induced depolarizations in the developing rat spinal cord. Perspect Dev Neurobiol 5:279-287. 